\title{
Partisan Conflict, News, and Investors' Expectations
}

Working Paper 2019-07

MARINA AzZimonti

November, 2019

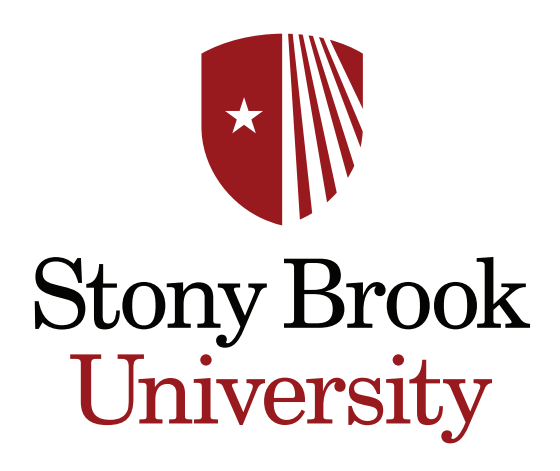




\title{
Partisan Conflict, News, and Investors' Expectations
}

\author{
Marina Azzimonti*
}

August, 2019

\begin{abstract}
In this paper, I consider the role of news provided by the media as signals used by investors to learn the underlying degree of partisan conflict. Partisan conflict is relevant for investment decisions because it affects the intensity of legislative effort aimed at (i) improving the institutional environment in which firms operate and (ii) instituting tax reforms. Higher partisan conflict makes tax reforms less likely but increases the probability of crises. These, in turn, affect the after-tax returns to investment. Whether the uncertainty and gridlock induced by partisan conflict is beneficial or detrimental for the economy depends on the status-quo level of taxes, on the identity of the party proposing policy reforms, and on the expected severity of crises. This is the case because even though a higher likelihood of bad economic outcomes is always negative for investment, stalemate makes tax-hikes less likely under some scenarios, and this may increase expected returns to investment. Agents do not observe the true degree of political disagreement (and hence the quality of policies), but can create expectations based on the observation of informative signals. Using a Bayesian learning model, I illustrate how these signals affect investment decisions by changing agents' expectations. I show that, to the extent crises are severe enough, an increase in the partisan conflict index (a summary of the signals observed) reduces expected returns and induces lower investment. Interestingly, investors react to news through changes in expectations even when there is no change in fundamentals.
\end{abstract}

JEL Classification: E3, H3.

* Stony Brook University. 


\section{Introduction}

The government, through the design of institutions and budgetary decisions, implements policies which affect the environment in which firms operate. These policies have an effect on the profitability of investment, and hence on the investment decisions of the private sector. Unfortunately, there is significant amount of uncertainty regarding the timing, impact, and effectiveness of government policies. Investors are therefore making decisions under varying degrees of uncertainty. The economic consequences of policy-related uncertainty has been documented in a series of recent papers which point to the political system as the main driver of the slow recovery from the Great Recession. For example, Baker, Bloom, and Davis (2016) compute an index of economic policy uncertainty (EPU) from newspaper articles and show that higher degrees of uncertainty are associated with lower aggregate investment in the US. Using the EPU index, Gulen and Ion (2016) show that approximately two thirds of the $32 \%$ drop in corporate investments observed during the Great Recession can be attributed to policy uncertainty. ${ }^{1}$ Azzimonti (2018a) argues that this uncertainty can be traced back to the degree of political discord in the US. Using a semantic search methodology to measure the frequency of newspaper articles reporting lawmakers' disagreement about policy, a partisan conflict index (PCI) is constructed. The author finds a negative relationship between the PCI and aggregate investment in the US (see Azzimonti, 2018a) and that foreign direct investment into the US tends to be lower when the (trade-specific) PCI rises (see Azzimonti, 2018b).

In this paper, I provide a theory consistent with these empirical findings. In particular, I consider the role of news provided by the media as signals used by investors to filter the true partisan conflict state. In a reduced-form political economy model with Bayesian learning, I illustrate how these signals affect investment decisions by changing investors' expectations. The returns to investment depend on the aggregate and idiosyncratic productivity of firms, on the level of taxes, and on the degree of partisan conflict. Partisan conflict is relevant for investment decisions because it affects the intensity of legislative effort aimed at (i) improving the institutional environment in which firms operate and (ii) instituting tax reforms (e.g. changing the level of taxes from the status-quo). While policymakers share the objective of improving the institutional environment in order to reduce the likelihood of crises, they disagree on the optimal level of taxes. There are three types of proposers in the model: left-winged (who prefer relatively high taxes), right-winged (who prefer relatively low taxes), and moderates (whose ideal tax rate takes an intermediate value). Partisan conflict affects their optimal effort level by making reforms more costly to the proposer. When parties are

\footnotetext{
${ }^{1}$ See Julio and Yook $(2012,2014)$ and Durnev (2010) for studies showing that political uncertainty (proxied by national election years) is associated with lower foreign direct investment in a panel of countries.
} 
polarized and the government is divided, partisan conflict is elevated, and legislative effort is lower. Therefore, higher partisan conflict makes tax reforms less likely, but increases the probability of crises. These, in turn, affect the after-tax returns to investment. Whether the uncertainty and gridlock induced by partisan conflict is beneficial or detrimental for the economy depends on the expected severity of crises and on the gap between current taxes and those preferred by the party proposing a reform. This is the case because even though a higher likelihood of bad economic outcomes is always negative for investment, stalemate makes tax-hikes less likely under some scenarios, and this may increase expected returns to investment. To the extent that crises are severe enough, the negative effects of partisan conflict on the quality of institutions dominate the benefits of inaction on tax reforms. As a result, partisan conflict is negatively associated with private investment in such environments.

The economic and political environments are presented in Section 2. Section 3 analyzes the case in which partisan conflict is perfectly observable. In Section 5 , the true value of partisan conflict is unobservable at the time of making decisions. Investors obtain imperfectly informative signals about true partisan conflict by reading newspapers, reports, and other sources of information. A model-counterpart of the partisan conflict index is constructed and its effects are analyzed in Section 5.3. Section 6 concludes.

Literature Review: In most political economy models, the ability to enact policies depends on how far the objectives of different policymakers are and on their political power. Modelling the complex political game where several branches of government are involved in deciding policy is non-trivial, so most papers in the literature make important simplifying assumptions. At one extreme, when the party's objectives are different, it is assumed that the party that wins an election acts as a dictator until a new election is held, as in Alesina and Tabellini (1990). At the other extreme, policy is the result of bargaining between identical legislators who need to divide resources, as in Baron and Ferejohn (1982), but due to symmetry all that changes across periods is the identity of agents receiving transfers (and not the size of transfers). The literature that followed mostly relied on the assumption that once the identity of the proposer or the party in power is revealed, the level of taxes (and other policy variables) is known. In other words, as long as there is no change in policymakers (e.g. no elections), there is no uncertainty about the path of policies. There is very little theoretical research about the causes of policy uncertainty in-between election periods, which is the focus of this paper.

This paper is also related to a growing literature studying the consequences of policy uncertainty on the aggregate economy. Early examples are Bernanke (1983), Pindyck (1993), 
and Dixit and Pindyck (1994). More recently, see Bloom (2009) Fernández-Villaverde and Rubio-Ramírez (2010,) Fernández-Villaverde, Guerrón, Kuester, and Rubio-Ramírez (2015), or Stokey (2013). A common assumption is that fiscal policy follows an exogenous process where its volatility changes over time. In periods of high variability, economic agents delay hiring, investment, or production decisions, and these amplify business cycles. ${ }^{2}$ Canes-Wrone and Park (2011) takes this one step further by connecting surges in policy uncertainty with the electoral cycle. They argue that agents have incentives to delay decisions that are subject to large reversibility costs right before elections, particularly when polarization is high and the election is competitive, as these imply high levels of economic policy uncertainty. Their main implication is a pre-election decline in investment. Azzimonti and Talbert (2013) propose an alternative channel by which political disagreement affects economic decisions. Using a standard partisan model of fiscal policy determination embedded in a neoclassical real business cycle model, they show that polarization increases induce economic policy uncertainty, causing long run investment to decline. The main difference between this paper and the ones mentioned above is that the partisan conflict index represents a signal about unobservable government dysfunction, rather than the degree of economic policy uncertainty.

Finally, the paper is related to literature on news shocks. The empirical finance literature has tried to identify the effect of news shocks on asset prices, and more recently on business cycle fluctuations, since the work of Beaudry and Portier (2006). As in this paper, the expectation formation process is modeled as a signal extraction problem in which news provide noisy information about the underlying state of the economy (see Beaudry and Portier, 2014). In this paper, news provides a signal used by investors to filter the true value of partisan conflict. The effects of political disagreement - the main driving force affecting the likelihood of recessions in this paper - are typically abstracted from. ${ }^{3}$ Exceptions are Pastor and Veronesi (2013) and Kelly, Pastor, and Veronesi (2013), where political news affect economic outcomes. In Pastor and Veronesi's model, agents are uncertain about the effects of current government policy on stock returns, as well as on the political costs associated from changing the status-quo. The main determinant of investment delays in their model is the 'wait and see' response of agents to policy uncertainty (e.g., the volatility of political costs), a second moment effect. In this paper, on the other hand, partisan conflict depresses investment more directly through a reduction in expected returns. This first moment effect is

\footnotetext{
${ }^{2}$ These papers are mostly concerned with uncertainty about government policy rather than uncertainty about the state of the economy. This is an important distinction in light of Bachmann, Elstner, and Sims (2013), who find (using US micro-data) that economic uncertainty is inconsistent with a wait-and-see hypothesis.

${ }^{3}$ Because partisan conflict affects tail risks, this paper is tangentially related to studies highlighting the effects of time-varying volatility caused by rare events (Gabaix, 2008; Shen 2005; Kelly and Jiang 2014, among others).
} 
present even when policy uncertainty is low, in sharp contrast with their results. In addition, I focus on political disagreement, while Pastor and Veronesi's main explanatory variable is economic policy uncertainty.

\section{Model}

\subsection{Private Investors}

Consider an infinite horizon economy populated by productive firms which own capital stock $K$ at the outset of the period and have access to a linear production technology

$$
f(z, K)=e^{z} K
$$

Total factor productivity $e^{z}$ depends on the firm's idiosyncratic productivity level $\varepsilon$ and the aggregate state of the economy $\nu$ as follows

$$
z=\varepsilon+\nu
$$

where $\varepsilon$ is normally distributed with mean $\mu$ and variance $\sigma^{2}$. The distribution of $\nu$ satisfies

$$
\begin{gathered}
\text { with probability } p: \quad \nu=\log (1-\kappa) \\
\text { with probability } 1-p: \quad \nu=0,
\end{gathered}
$$

with $\kappa<1$. The realization $\nu=0$ indicates 'normal times' whereas $\nu=\log (1-\kappa)$ indicates a 'crisis' where productivity is significantly lower than average. ${ }^{4}$

The capital stock follows

$$
K^{\prime}=I+(1-\delta) K^{\prime}
$$

where $\delta$ denotes the depreciation rate of capital, $K^{\prime}$ the stock of capital next period, and $I$ denotes investment. The firm faces adjustment costs of investment $\Phi(I)$, that can be interpreted as costs of installation and de-installation of capital.

Assumption 1 Adjustment costs are increasing and convex in investment, $\Phi_{I}>0$ and $\Phi_{I I}>0$.

\footnotetext{
${ }^{4}$ The choice of $\nu=0$ for normal times is without loss of generality for the main result and given the other assumptions of the model. It was done to simplify the exposition.
} 
Revenues are subject to proportional taxes $\tau$, which affect the returns to investment. The determination of fiscal policy will be described in the next section. For the moment, it is important to know that the path of future taxes is uncertain. Managers running these firms decide how much to invest given total factor productivity $z$, current taxes $\tau$, and expectations about the evolution of $z$ and $\tau$ in order to maximize the value of the firm $V(z, K)$

$$
\begin{gathered}
V(z, K)=\max _{\left\{I, K^{\prime}\right\}}\left\{\quad(1-\tau) f(z, K)-I-\Phi(I)+\frac{1}{1+r^{*}} \mathbb{E}\left[V\left(z^{\prime}, K^{\prime}\right) \backslash \Omega\right]\right\} \\
\text { s.t. } I=K^{\prime}-(1-\delta) K,
\end{gathered}
$$

with $\Omega$ denoting the available information to the investor at the time of making decisions. We sometimes refer to managers as investors in what follows.

Letting $Q$ denote the current valued Lagrange multiplier on constraint (1), we have that

$$
Q=\Phi_{I}+1
$$

Managers invest such that the marginal cost of an additional unit of capital (which equals 1 plus the marginal adjustment cost) equals the shadow price of capital $Q$, also known as Tobin's Q. The optimality condition with respect to $K^{\prime}$ is

$$
Q=\frac{1}{1+r^{*}} \mathbb{E}\left[\left(1-\tau^{\prime}\right) f_{K}^{\prime}+(1-\delta) Q^{\prime} \backslash \Omega\right]
$$

where $f_{K}^{\prime}$, the marginal product of capital next period, represents the returns to investment. Eq. (3) is the Euler equation for the firm, in which the (shadow) price of capital equals the expected discounted value of the return on capital next period plus the future shadow price of capital (or re-sell value). After manipulating eqs. (2) and (3), we obtain

$$
\Phi_{I}+1=\frac{1}{1+r^{*}} \mathbb{E}_{z^{\prime}, \tau^{\prime}}\left[R\left(z^{\prime}, \tau^{\prime}\right)+(1-\delta)\left[\Phi_{I}^{\prime}+1\right] \backslash \Omega\right]
$$

where $R\left(z^{\prime}, \tau^{\prime}\right)=\left(1-\tau^{\prime}\right) e^{z^{\prime}}$ is the after-tax return on investment. This dynamic equation determines the evolution of capital over time. In general, this difference equation does not allow for an analytical representation. Under the following set of conditions, namely full depreciation and quadratic adjustment costs, investment can be solved for in closed form.

Assumption 2 There is full depreciation $\delta=1$ and adjustment costs satisfy

$$
\Phi(I)=\frac{1}{2} \gamma I^{2}
$$


Under the assumption, and using the Euler equation of firms eq. (4), investment becomes

$$
I=\frac{1}{\gamma}\left[\frac{1}{1+r^{*}} \mathbb{E}_{z^{\prime}, \tau^{\prime}}\left(R\left(z^{\prime}, \tau^{\prime}\right) \backslash \Omega\right)-1\right]
$$

From the expression, it is easy to see that investors are subject to two sources of risk in this economy. One is of economic nature, namely the productivity shocks $z^{\prime}$. The second one relates to fiscal policy, as the future value of taxes $\tau^{\prime}$ is unknown at the moment of making decisions. Both, by changing the returns to capital, affect investment decisions.

\subsection{The Government}

The government affects the returns to investment through fiscal policy and the institutional environment. At every point in time, there is a tax code determining $\tau$ and a set of institutions that affect the probability of a crisis $p$. Changes in the tax code and the institutional environment are complex processes that, in most countries, require the approval of several branches of the government. For example, in the United States, Congress takes steps known as the legislative process to pass a Federal law. This process begins when a Senator or Representative prepares a proposed law, called a 'bill.' It ends when Congress approves the bill and sends it to the President. When the President signs the bill, it then becomes law.' (US Department of Treasury). ${ }^{5}$ The process requires significant effort from the proposer, who drafts the initial bill and needs to obtain co-sponsors. There are several rounds of negotiation between the first proposal and the bill that eventually passes. In addition, many proposed bills are not approved by a majority in the House of Representatives or in the Senate, and/or may be vetoed by the President. Therefore, whether a proposed bill is implemented or not is typically uncertain despite the proposer's efforts. The process of implementing reforms defines a complicated political game whose outcome depends on how different the objectives of legislators are, the distribution of their political power, and the degree of disagreement between the executive and legislative branches. Rather than modeling the process in detail, I will take a parsimonious view of the legislative process.

\subsection{Legislative process}

Given the existing set of institutions and the tax code, a proposer is chosen at random every period from the pool of legislators. I assume that every legislator type has the same chances of becoming a proposer (e.g. there is symmetry), denoting the probability of becoming a proposer with $\pi$. The chosen legislator can initiate a proposal to reform the institutional

\footnotetext{
${ }^{5}$ See https://www.treasury.gov/resource-center/faqs/Taxes/Pages/writing.aspx
} 
environment and/or implement changes in the tax code. The likelihood of a reform being implemented depends on how conducive the political environment is, which is summarized by the degree of partisan conflict $c$. Partisan conflict aims at capturing, in reduced form, a complex political process where polarization (e.g. different views about policy) and political power (e.g. the ability to implement a desired policy) are important determinants of policy outcomes. When partisan conflict is high, the resulting gridlock in Congress leads to inaction and a low probability of reforms. On the other hand, when partisan conflict is low, reforms are easy to pass, but policy becomes more volatile.

I assume that there are three types of proposer: Left-wing $L$, Right-wing $R$, and Moderates, $M$. While they all share the vision that crises are negative for the economy and hence should be prevented, they disagree on the optimal level of taxation. In particular, their preferred tax rates are $\tau_{R}<\tau_{M}<\tau_{L}$, where $\tau_{i}$ is the tax rate preferred by policymaker $i$. To simplify the exposition, I assume symmetry in preferred tax rates, with $\tau_{M}=\bar{\tau}, \tau_{L}=\bar{\tau}+\triangle$ and $\tau_{R}=\bar{\tau}-\triangle$. The parameter $\triangle$ captures the degree of polarization in society. When $\triangle=0$ there is no disagreement over taxes among legislators, as $\triangle$ increases the distance between their preferred tax rates widens.

In non-election years, a proposer of type $i$ chooses the level of effort to be exerted in improving the institutional environment $x$ and / or modifying the tax code $n$. There is an election every $T$ periods that determines the identity of the new proposer and the degree of partisan conflict $c .^{6}$

A better institutional environment is assumed to reduce $p$, the probability of a crisis. Examples are banking regulation (e.g. reserve requirements and deposit insurance), financial reforms (e.g. Dodd-Frank), budget rules (e.g. a balanced budget amendment to prevent excessive debt creation and hence the likelihood of defaults), enhancing homeland security (e.g. the Intelligence Reform and Terrorism Prevention Act of 2004), or simply managing the federal budget to reduce the risk of 'fiscal cliffs'. The level of effort $x$ devoted to improve the institutional environment exerted by the proposer enhances the probability of preventing negative events by reducing tail risks. To capture this, I assume that $p$ is a decreasing function of effort $x$ :

$$
p(x)=\frac{1}{m} e^{-x},
$$

where $m$ is a positive number. When the proposer exerts little to no effort, the probability of a crisis is at its peak, $\lim _{x \rightarrow 0} p(x)=\frac{1}{m}$. As $x$ increases, the probability of a crisis declines

\footnotetext{
${ }^{6}$ It would be straightforward to extend the model to allow the identity of the proposer to change in nonelection years as well. But this would significantly complicate the notation without any additional insights to the model.
} 
monotonically to zero, $\lim _{x \rightarrow \infty} p(x)=0$. I am assuming that the gains from improving the institutional environment are identical to all policymakers, as everyone loses when a severe crisis hits a country.

In addition, the proposer can exert effort $n$ to modify the tax code. I assume that more effort increases the probability $q$ of changing taxes from the current rate $\tau$ to policymaker $i$ 's preferred value $\tau_{i}$, with

$$
q(n)=1-e^{-n}
$$

When no effort is exerted, $q(0)=0$, implying that the tax rate remains at the status quo level $\tau$. As $n$ grows, so does the likelihood of a tax reform. There is a one-period lag in the implementation of the new policy. This means that if the attempt to reform the tax code is successful, then $\tau^{\prime}=\tau_{i}$.

Exerting effort to reform the institutional environment $(x)$ or the tax code $(n)$ is costly economically (e.g. data gathering, policy design, etc.) and politically, as the reform may create redistribution or may alienate a party's political base. Polarization and divided government make policy implementation more politically costly and, therefore, less likely. To capture this, I assume that the total cost of implementing a reform depends on both, the levels of effort, and the degree of partisan conflict $c$,

$$
T C(x, n)=\alpha(c) x+\beta(c) n,
$$

where $\alpha(c)$ and $\beta(c)$ are increasing and convex functions of partisan conflict that capture the deadweight loss of political bickering.

We can think of partisan conflict as resulting from the interaction between two parties with different objectives in the political arena. Policymakers' ideological differences (polarization) are clearly important determinants of political disagreement. The further apart parties' views over policies are, the higher the level of conflict should be, and hence the more difficult it would be to reach consensus. How political power is divided between the two parties must also affect the degree of conflict (as suggested by Alesina and Rosenthal, 1995). Consider the extreme case of one particular party controlling both chambers of Congress and the presidency. Then partisan conflict should be low, regardless of how polarized these parties are. There are other factors affecting the political environment, such as the influence of interest groups, the political affiliation of the President and his relationship with both chambers of Congress, the composition of Congress committees, etc. Rather than modeling the determinants of a complex political process, I focus on this reduced form in order to concentrate on the implications of partisan conflict on investment decisions. It would be interesting, in future 
work, to model these interactions explicitly.

\subsection{Proposer's Maximization Problem}

The proposer exerts effort to prevent crises and to modify the tax code when the current tax rate is not her preferred one. The expected net gain of making a reform, $\Pi_{i}(x, n ; \tau)$ given her type $i$ and the status-quo level of taxes $\tau$ is

$$
\Pi_{i}(x, n ; \tau)=[1-p(x)]+q(n)\left|\tau-\tau_{i}\right|-T C(x, n),
$$

where $1-p(x)$ represents the expected benefit of improving the institutional environment, the term $q(n)\left|\tau-\tau_{i}\right|$ is the expected gain from a change in the tax code, and $T C(x, n)$ is the total cost of exerting effort today. Because the chances of being a proposer next period $\pi$ are independent of $x, n$, and type, there is no dynamic link between the choices made today and the ones made tomorrow. In other words, conditional on being a proposer, the maximization problem does not involve future periods and it can be written as a sequence of quasi-static problems. We can then write the proposer's objective as

$$
\max _{\{x, n\}} \Pi_{i}(x, n ; \tau)
$$

Note that if the current tax rate is $\tau=\tau_{i}$, then there is no incentive to reform the tax code. However, every proposer - regardless of its type - would like to avoid a crisis. Hence, it is always optimal to set $x>0$. Moreover, due to the additive separability assumption in preferences, all proposer types choose the same effort level for $x$. The first order condition with respect to $x$ equates the marginal benefit of effort (e.g. making crises less likely) to its marginal cost,

$$
-\frac{\partial p(x)}{\partial x}=\frac{\partial T C(x, n)}{\partial x}
$$

and the optimality condition with respect to $n$ is to exert no effort when taxes are at $i$ 's preferred point, $\tau=\tau_{i}$, or choose $n$ such that

$$
\frac{\partial q(n)}{\partial n}\left|\tau-\tau_{i}\right|=\frac{\partial T C(x, n)}{\partial n}, \quad \text { if } \quad \tau \neq \tau_{i}
$$

These yield optimal effort levels for crisis prevention $\mathcal{X}(c)$ and tax reforms $\mathcal{N}_{i}(c, \tau)$, as functions of partisan conflict. Associated to these choices, are the resulting probabilities $\mathcal{P}(c)$ and $\mathcal{Q}_{i}(c, \tau)$. 


\section{Partisan Conflict and Government Policy}

In this section, I describe the effects of partisan conflict on government policy assuming that partisan conflict is perfectly observable to investors. The next section analyzes the case of imperfect information and the role of news about partisan conflict on investment.

Assumption 3 Assume that $\alpha(c)$ and $\beta(c)$ satisfy

$$
\alpha(c)=\frac{1}{m}\left(\epsilon+\theta e^{-\frac{1}{c}}\right) \quad \text { and } \quad \beta(c)=\frac{\theta}{v} e^{-\frac{1}{c}} .
$$

Legislative effort levels $\mathcal{X}$ and $\mathcal{N}_{i}$ can be solved for analytically as functions of the status quo tax rate $\tau$, the identity of the proposer, $i$, and of partisan conflict $c$. These are summarized in Lemma 3.1.

Lemma 3.1 Under Assumption 3, and given status quo taxes $\tau$, we can show the following

i. Legislative effort levels $x$ and $n$ for proposer type $i$ satisfy

$$
\begin{aligned}
\mathcal{X}(c) & =-\ln \left(\epsilon+\theta e^{-\frac{1}{c}}\right) \\
\mathcal{N}_{i}(c, \tau) & =\left\{\begin{array}{cc}
-\ln \left(\frac{\theta}{v\left|\tau-\tau_{i}\right|} e^{-\frac{1}{c}}\right) & \text { if } \tau \neq \tau_{i} \\
0 & \text { otherwise }
\end{array}\right.
\end{aligned}
$$

ii. The likelihood of a recession (or crisis) is characterized by

$$
\mathcal{P}(c)=\frac{1}{m}\left(\epsilon+\theta e^{-\frac{1}{c}}\right) .
$$

iii. The probability of a tax reform is

$$
\mathcal{Q}_{i}(c, \tau)=\left\{\begin{array}{cl}
1-\frac{\theta}{v\left|\tau-\tau_{i}\right|} e^{-\frac{1}{c}} & \text { if } \tau \neq \tau_{i} \\
0 & \text { otherwise }
\end{array}\right.
$$

Proof 3.1 Optimal effort levels $x$ and $n$ result from solving Problem 8. The probability of a recession is obtained by replacing $\mathcal{X}(c)$ into eq. (6). The probability of a tax reform is obtained by replacing $\mathcal{N}_{i}(c, \tau)$ into eq. (7). 
The level of effort exerted to improve the institutional environment $\mathcal{X}(c)$ is independent of the legislator type. From the expressions in Lemma 3.1, it is easy to see that partisan conflict decreases effort $\mathcal{X}$ and increases the likelihood of crises:

$$
\frac{\partial \mathcal{X}(c)}{\partial c}<0 \quad \text { and } \quad \frac{\partial \mathcal{P}(c)}{\partial c}>0
$$

That political dysfunction is associated with a lower level of legislative effort is consistent with the observation that legislative productivity declines when gridlock intensifies (Binder, 1999). Figure 1 depicts legislative effort to improve the institutional environment $\mathcal{X}(c)$ as a function of partisan conflict (left panel), together with the resulting probability of a crisis $\mathcal{P}(c)$ (right panel) for a numerical example.
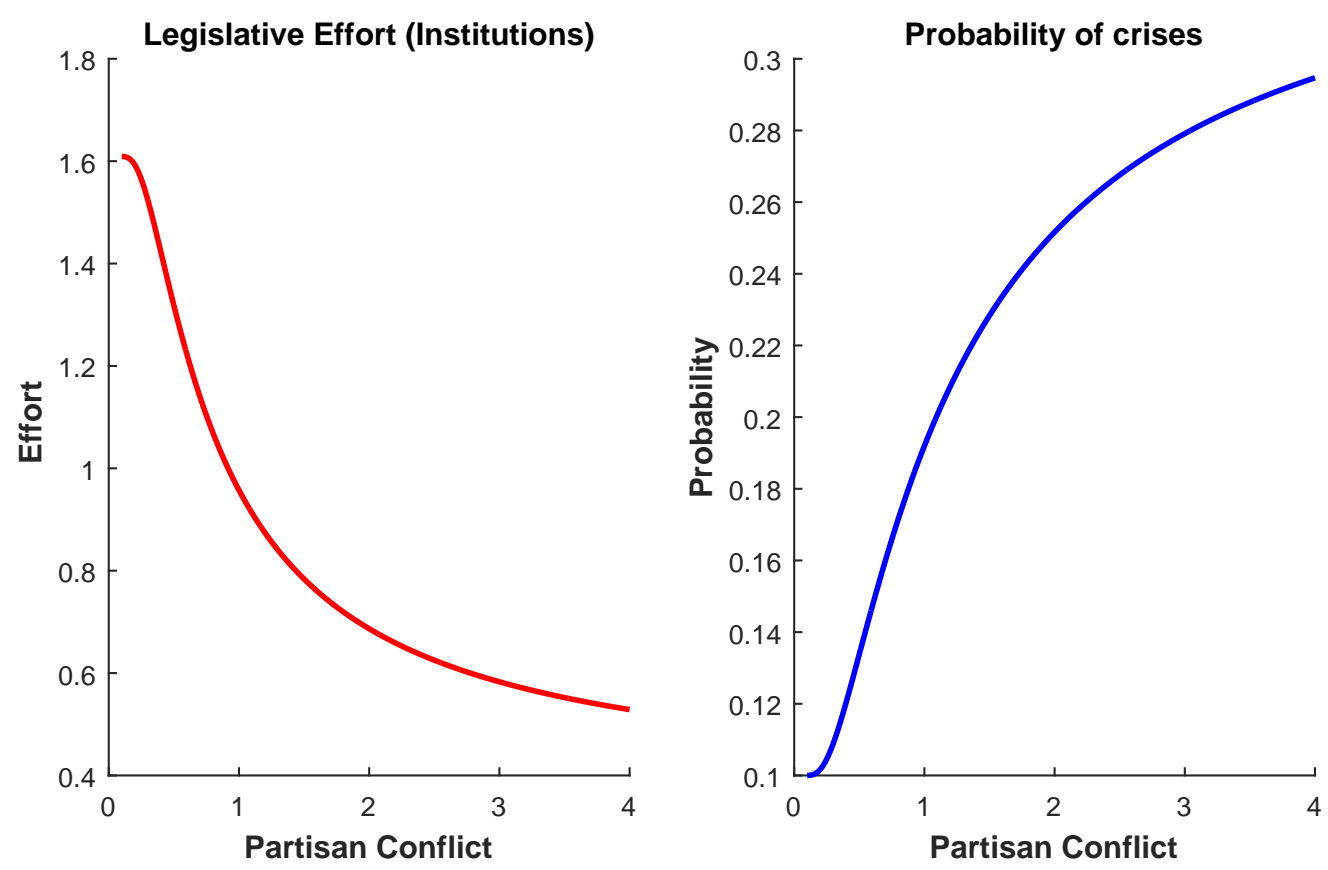

Figure 1: Legislative effort (institutions) and probability of a crisis as functions of partisan conflict. Parameters: $\theta=0.5, m=2, \epsilon=0.2, \alpha=10$, and $v=4$.

The effects of partisan conflict on the level of effort exerted to modify the tax code $\mathcal{N}_{i}(c, \tau)$ and the resulting probability of reforms $\mathcal{Q}_{i}(c, \tau)$ are illustrated in Figure 2. These are shown for the case where $\tau \neq \tau_{i}$, that is, when the status quo is different from the proposer's preferred tax rate $\tau_{i}$. Due to symmetry, there are only two relevant cases: (i) the current tax rate is the one preferred by a moderate $\tau=\bar{\tau}$ and the proposer is $i \in\{R, L\}$ (see the solid line), or (ii) the current tax rate is $\tau_{i}$ and the proposer is $j \neq i$, for $i, j \in\{R, L\}$ (see the 

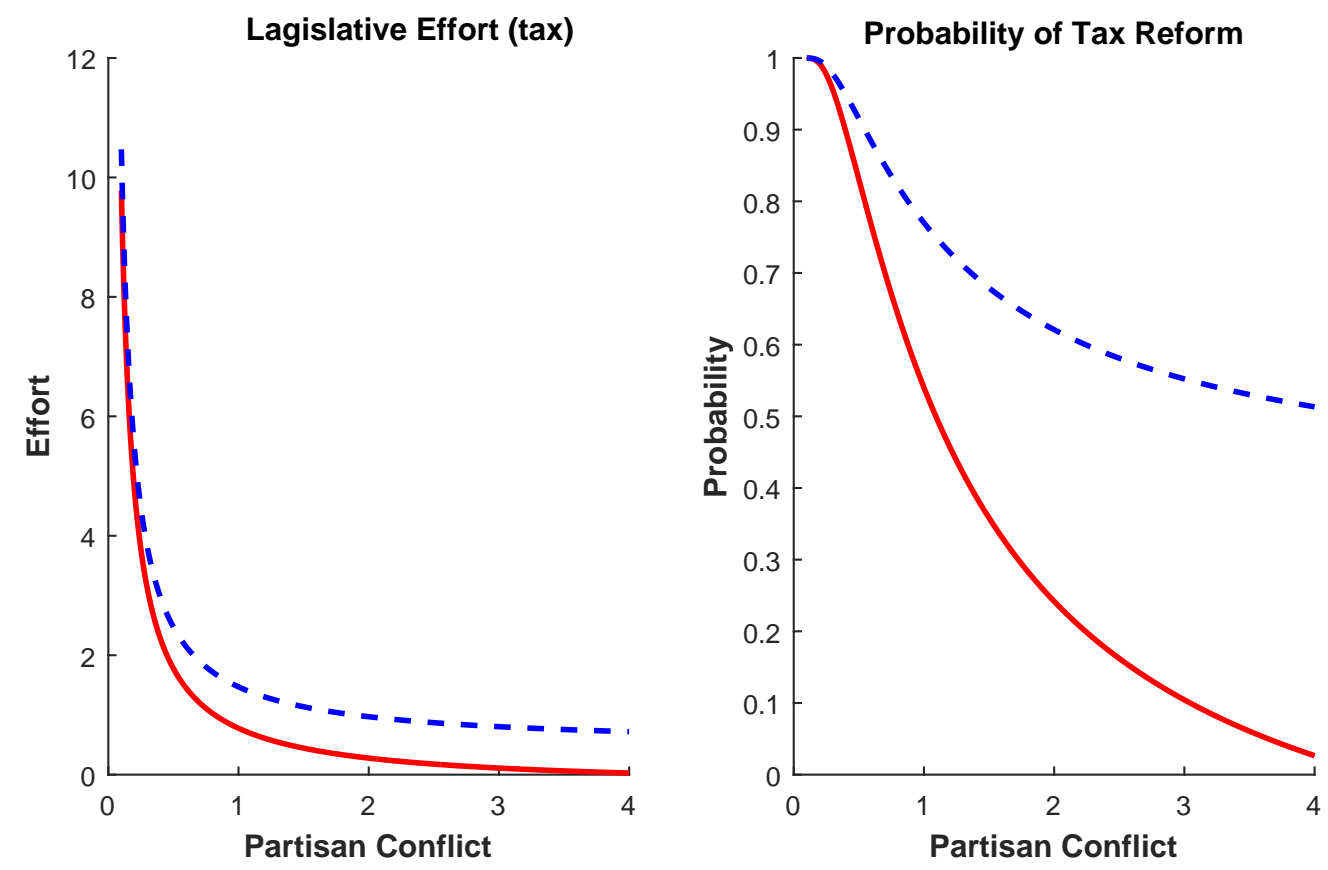

Figure 2: Legislative effort ( $\operatorname{tax})$ and probability of a tax reform of legislator $i$ as functions of partisan conflict. Solid line $\tau=\bar{\tau}$, dashed line $\tau=\tau_{j}, j \neq i$. Parameters: $\theta=0.5, m=2, \epsilon=0.2, \alpha=10$, $v=4, \triangle=0.1, \bar{\tau}=0.3$.

dashed line). ${ }^{7}$ Because the preferred tax rate of legislator $i$ is further away from $\tau_{j}$ than from $\bar{\tau}$, the gains from trying to reform the tax code are larger. Hence, the proposer exerts more effort in order to increase the probability of a reform. This is illustrated by the fact that the dashed line is above the solid one in Figure 2.

It is instructive to compute the conditional expectation of tomorrow's taxes from today's perspective. The relevant information set $\Omega$ is given by the state variables $\{\tau, c, i\}$, namely the status quo tax, the level of partisan conflict, and the identity of the proposer today. Conditional on $\Omega$, the expected value of $\tau^{\prime}$ is

$$
\begin{aligned}
\mathbb{E}_{\tau^{\prime} / \Omega} & =\mathcal{Q}_{i}(c, \tau) \tau_{i}+\left(1-\mathcal{Q}_{i}(c, \tau)\right) \tau \\
& =\tau+\mathcal{Q}_{i}(c, \tau)\left[\tau_{i}-\tau\right]
\end{aligned}
$$

The first row follows from the fact that a tax reform is successful with probability $\mathcal{Q}_{i}(c, \tau)$ when $i$ is the proposer. A tax hike is expected when the proposer's preferred point is above the status quo $\tau_{i}>\tau$, whereas a tax cut is expected when $\tau_{i}<\tau$. As long as $c>0$, investors

\footnotetext{
${ }^{7}$ Note that the case where the current rate is $\tau_{i}$ for $i \in\{R, L\}$ and the proposer is a moderate is identical to case (i).
} 
will not know the future level of taxes with certainty.
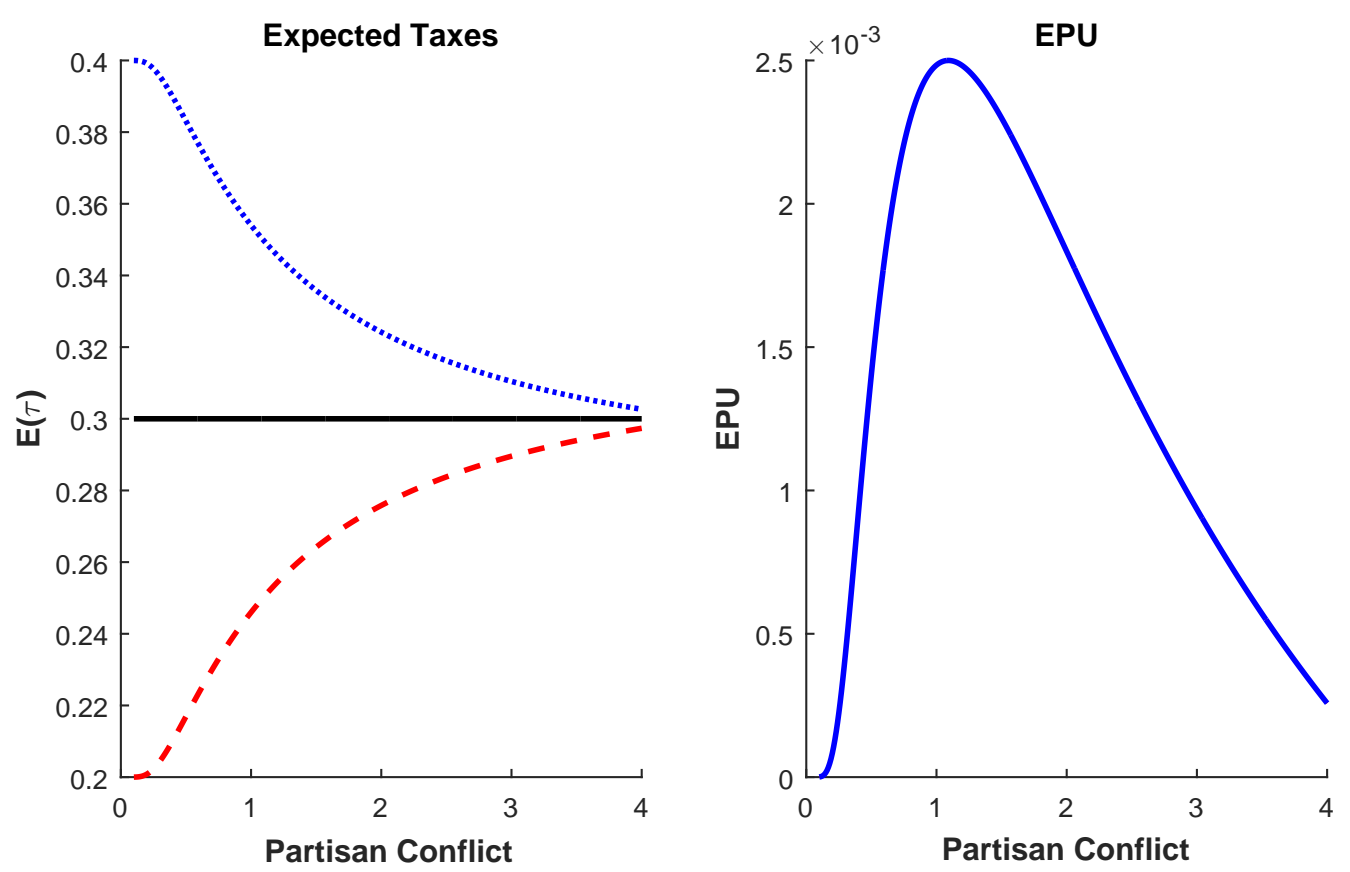

Figure 3: Left panel: Expected taxes conditional on $\tau=\bar{\tau}$ as a function of partisan conflict. Solid line $i=M$, dotted line $i=L$, dashed line $i=R$. Right panel: Economic Policy Uncertainty as a function of $c$. Parameters: $\theta=0.5, m=2, \epsilon=0.2, \alpha=10, v=4, \triangle=0.1, \bar{\tau}=0.3$.

Suppose that the current tax is the preferred tax of a moderate candidate, $\tau=\bar{\tau}$. It is easy to see from the expression above that the largest tax hike is expected when there is little partisan conflict and the proposer is left-winged, $i=L$. This is because left wing proposers would want to increase taxes, and they are very likely to reform the tax code when facing little opposition from other legislators (i.e. when partisan conflict is low). Similarly, the maximum tax-cut is expected when the proposer is right-winged and partisan conflict is low. At the other extreme, when partisan conflict is really large, tax reforms are unlikely. Due to gridlock, taxes are expected to remain unchanged at $\tau=\bar{\tau}$. These are illustrated in the left panel of Figure 3. The figure depicts $\mathbb{E}_{\tau^{\prime} / \Omega}$ with $\tau=\bar{\tau}$ as a function of partisan conflict $c$ for different identities of the proposer. The solid line represents the case of $i=M$. Because the status quo is the preferred level by proposer $M$, taxes are expected to remain unchanged regardless of $c$. The dotted line illustrates the case $i=L$, whereas the dashed line represents $i=R$. Expected taxes are lower than the status quo under a $R$-winged proposer, but the gap narrows as partisan conflict rises, making tax-cuts less likely. Tax hikes are expected under 
a $L$-winged proposer, but the increase declines with $c$.

Uncertainty The effect of economic policy uncertainty (EPU) on private investment has received a lot of attention on the empirical literature in recent years (see, for example Baker, Bloom, and Davis 2016). This model features policy uncertainty because, despite legislative effort, reforms are not always implemented and changes in the institutional environment are not always successful. In other words, because the path of government policy is uncertain from today's perspective. Our notion of EPU is defined next.

Definition 3.1 'Economic policy uncertainty' refers to the conditional variance of fiscal policy, $\operatorname{Var}(\tau \mid \Omega)$ given the information set $\Omega$.

$$
\operatorname{Var}(\tau \mid \Omega)=\mathcal{Q}_{i}(c, \tau)\left[1-\mathcal{Q}_{i}(c, \tau)\right]\left(\tau_{i}-\tau\right)^{2}
$$

It is characterized in the following Lemma.

Lemma 3.2 The relationship between partisan conflict, $c$, and economic policy uncertainty, $\operatorname{Var}(\tau \mid \Omega)$, is non-monotonic when $\tau \neq \tau_{i}$

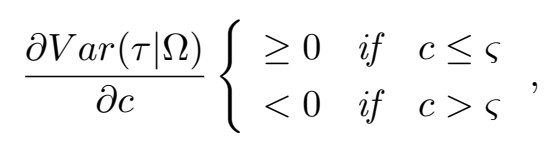

where

$$
\varsigma=-\frac{1}{\ln \left(2 \frac{v}{\theta}\left|\tau-\tau^{i}\right|\right)} .
$$

Proof 3.2 See Appendix \%.1.

Clearly, if the status-quo is the one preferred by the proposer, there is no uncertainty: taxes remain unchanged. When the degree of partisan conflict is low, there is little EPU because a tax reform is very likely when the current tax is not what the proposer would prefer, $\tau \neq \tau_{i}$. At the other extreme, if $c$ is very large, the probability of a reform is very low, and hence there is little uncertainty about the tax code. EPU is maximal for intermediate levels of partisan conflict, because these are the periods where, even though legislators exert significant effort, opposition makes the chances of a reform close to 50\%. The relationship between EPU and $c$ is depicted in the right panel of Figure 3 for the case where $\tau=\bar{\tau}$ and $i \in\{L, R\}$. That is, when the proposer is $R$ or $L$ and taxes are those preferred by a moderate legislator. The plot does not depend on whether $i=L$ or $i=R$ due to the symmetry in preferences assumed at the outset of the paper. 


\section{Partisan Conflict and Private Investment}

From the discussion above, partisan conflict - through its effect on government policy - has two effects on the level of investment: on the one hand, it increases the probability of negative outcomes, $\mathcal{P}(c)$, because the proposer does not have incentives to exert effort knowing that improving the institutional environment is politically costly. This is clearly negative for investment. On the other hand, partisan conflict also reduces the probability of implementing a tax reform. This can be positive or negative for investment depending on the status quo tax rate $\tau$. If current taxes are lower than the proposer's preferred value, stalemate makes tax hikes less likely, which fosters investment. But the opposite is true when current taxes are lower than the proposer's ideal point. Lemma 4.1 characterizes the first force by focusing on the effects of $c$ on pre-tax returns.

Lemma 4.1 Partisan conflict reduces the pre-tax return on investment

$$
\frac{\partial E\left(e^{z} / c\right)}{\partial c}<0
$$

Proof 4.1 See Appendix 7.2

The after-tax return on investment can be re-written, after some manipulations, as follows

$$
\mathbb{E}_{z^{\prime}, \tau^{\prime}}\left(e^{z^{\prime}}\left(1-\tau^{\prime}\right) \backslash \Omega\right)=\underbrace{e^{\frac{2 \mu+\sigma^{2}}{2}}}_{\text {TFP }} \underbrace{[1-\kappa \mathcal{P}(c)]}_{\text {Institutions }} \underbrace{\left[1-\tau+\frac{\tau-\tau_{i}}{\left|\tau-\tau_{i}\right|} \frac{\theta}{v} e^{\left.-\frac{1}{c}\right]}\right.}_{\text {Fiscal Policy }}
$$

The first term is the average return to investment in normal times (e.g. when $\kappa=0$ ), before taxes. Recall that $\mu$ and $\sigma$ are the mean and standard deviations, respectively, of the idiosyncratic shock $\epsilon$; so the term reflects the productivity of the average firm in the absence of crises. The second term is the expected value of the aggregate shock $\nu$. It captures how the institutional environment affects the returns to investment. It is smaller than one when a crisis generates a recession, that is when $\kappa>0$. Because the probability of a recession $\mathcal{P}(c)$ depends positively on partisan conflict, the second term reduces expected returns as $c$ rises. The last term reflects the effect of expected taxes on the returns to investment. When taxes are expected to remain at the status quo level, they reduce the return to investment by $(1-\tau)$, regardless of the degree of partisan conflict. When the current proposer's ideal point is greater than the status quo, $\tau_{i}>\tau$, a tax hike is expected with some probability, which would reduce the returns to investment even further. Because partisan conflict increases the possibility of a gridlock where taxes remain unchanged, higher values of $c$ are actually 
beneficial for investment. If a tax cut is expected because $\tau_{i}<\tau$, then higher values of partisan conflict reduce the probability of a tax-cut and hence are associated with lower investment returns.
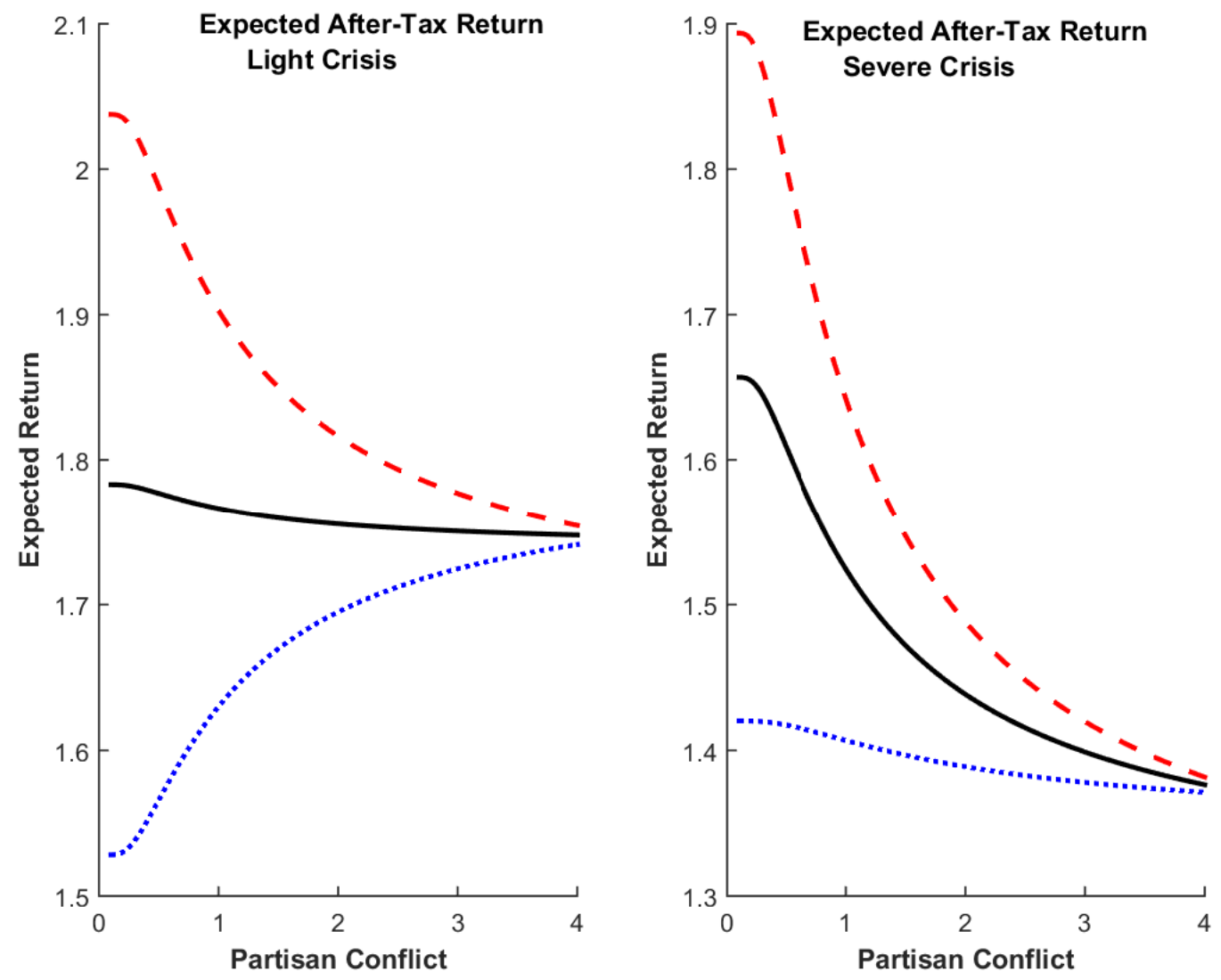

Figure 4: Expected after-tax return as a function of partisan conflict. Left panel: $\kappa=0.1$ and right panel $\kappa=0.8$. Solid line $i=M$, dotted line $i=L$, dashed line $i=R$. Parameters: $\theta=0.5, m=2$, $\epsilon=0.2, \alpha=10, v=4, \triangle=0.1$, and the status quo tax $\tau=\bar{\tau}=0.3$.

The analysis above suggests that partisan conflict and private investment are not always negatively related. This is because there are two opposing forces at play. On the one hand, higher $c$ always pushes the return to investment down through its detrimental effect on the institutional environment. On the other hand, gridlock constrains the ability of the proposer to implement a tax hike. The magnitude of $\kappa$, measuring the severity of the crisis and the distance between $\tau_{L}$ and the status quo $\tau$ determine which effect dominates.

Figure 4 illustrates how these forces can shape expected returns through a numerical example. Because investment decisions are proportional to after-tax returns, it is sufficient 
to understand how the latter responds to partisan conflict. The parameters are the same as those used in previous examples, namely $\theta=0.5, m=2, \epsilon=0.2, \alpha=10, v=4, \triangle=0.1$, and the status quo tax $\tau=\bar{\tau}=0.3$. The only difference between the left panel and the right panel is the severity of the recession. The 'light crisis' case refers to a parametrization where $\kappa=0.1$, whereas the 'severe crises' assumes $\kappa=0.8$.

When the current tax rate is the one preferred by a moderate, and the proposer is of that type (solid line in both figures), the only effect on expected return is through the realization of the aggregate shock. Since taxes remain constant, expected returns after tax go down as $c$ increases because the probability of the crises increases with partisan conflict. The slope is steeper with a severe crises (right panel) because the realized value of $\kappa$ is higher.

When the proposer is right-winged (dashed line), a tax cut is expected from the status quo $\bar{\tau}$. This increases after-tax returns in the absence of partisan conflict, as seen by the distance between the solid line and the dashed line at the origin. Expected returns decrease with partisan conflict for two reasons: first, because the tax cut is less likely to materialize when facing strong opposition (fiscal policy effect); second, because legislative effort to reduce the probability of crises is lower, increasing the chances of a negative TFP shock (institutional environment effect). The two effects, then, go in the same direction in this case. As before, the slope is steeper in the case where the crisis is more severe (right panel).

When the proposer is left-winged (dotted line), the two forces shaping after-tax returns move in opposite direction. With low levels of partisan conflict, a tax-increase is expected, reducing expected returns. As $c$ increases, so does the probability of a crisis, also reducing after-tax returns. But gridlock reduces the likelihood of the tax hike. When $\kappa$ is small (left panel), the fiscal policy effect dominates and hence partisan conflict is associated with higher returns. When tail events are more severe, the second force (e.g. institutional environment effect) dominates, so increases in $c$ are associated with reductions in after-tax returns.

Implications: From the example, we learn that empirical estimates of the effects of partisan conflict on private investment must conditioned on: (i) the identity of the decision-maker and (ii) the current level of taxes relative to historical measures (or a measure of the ideal tax of the proposer). We would expect that the responsiveness of investment to partisan conflict would be smaller (and even change sign) when the proposer is left-winged and taxes are lower than the policymaker's ideal point. In all other cases, we would expect a negative correlation between partisan conflict and private investment. 


\section{Imperfect Information}

In this section, I relax the perfect information assumption. In particular, I assume investors do not know the true value of partisan conflict $c$ at the time of making decisions. This key assumption captures the idea that the profitability of investment is not only risky, but also uncertain (e.g. features Knightian uncertainty). Since the probability of a crisis $\mathcal{P}(c)$ depends on partisan conflict $c$ - which is unobservable - the distribution of TFP shocks is unknown. Moreover, as the probability of a tax reform $\mathcal{Q}_{i}(c, \tau)$ also depends on $c$, the future path of fiscal policy is also uncertain.

\subsection{Information Structure}

The prior distribution of $c$ at time 0 is assumed to be inverse-gamma with parameters $\alpha_{0}$ and $\beta_{0}$,

$$
c \sim \operatorname{IG}\left(\alpha_{0}, \beta_{0}\right) .
$$

Investors observe $n$ unbiased signals $s^{i}$, with $i \in\{1, \ldots, n\}$, between the outset of any period and the time of investment. It is assumed that signals $s^{i}$ are drawn from an exponential distribution centered around the true value of partisan conflict $c$,

$$
s^{i} \sim \exp (c)
$$

Since this distribution has positive support, $s^{i}$ always takes non-negative values. ${ }^{8}$ Intuitively, these signals capture period $t$ 's flow of political news associated with future policies or a potential reform to the institutional environment. Investors observe political speeches, debates, and negotiations through news outlets on a daily basis. These events provide information about the degree of political disagreement allowing them to revise their beliefs about the likelihood of effective policies being implemented or tax reforms being enacted.

Let $\hat{\alpha}$ and $\hat{\beta}$ denote investors' prior beliefs over the parameters of this distribution at the beginning of a period. After observing the signals, agents update their beliefs using Bayes' rule. The posterior distribution of $c$ at the time of making an investment decision during non-election years (e.g. at any period $t<T$ ), is thus given by an inverse gamma $\operatorname{IG}\left(\hat{\alpha}^{\prime}, \hat{\beta}^{\prime}\right)$

\footnotetext{
${ }^{8}$ Recall that the pdf of an exponential distribution is $f(s)=\frac{1}{c} e^{-\frac{s}{c}}$, for $s \geq 0$ and 0 otherwise. It is worth mentioning that the distributional assumptions determining the stochastic behavior of priors (inversegamma) and news-shocks (exponential) are made primarily for tractability. The results are robust to normally distributed prior $c$ and signals $s$. However, the normality assumption could result in negative realizations of partisan conflict or posterior probability of crises outside of the $[0,1]$ interval. The IG-exponential assumption, on the other hand, ensures that probabilities remain in the $[0,1]$ interval and that partisan conflict is positive.
} 
where primes denote the next period and the posterior parameters evolve according to

$$
\hat{\alpha}^{\prime}=\hat{\alpha}+n, \quad \text { and } \quad \hat{\beta}^{\prime}(\bar{s})=\hat{\beta}+n \bar{s} .
$$

In the expression above, $\bar{s}$ denotes the sample mean $\bar{s}=\sum_{i=1}^{n} s^{i} / n$ of the political signals observed in the current period. The resulting posterior distribution of $c$ is computed in Appendix 7.3. In what follows, we refer to the sample mean $\bar{s}$ as the partisan conflict index, a news-generated indicator that summarizes investors' information about political disagreement. This definition is consistent with the empirical counterpart estimated by Azzimonti (2018). It is useful to define the following terms.

Definition 5.1 The 'Partisan conflict index' (PCI) is the sample mean $\bar{s}=\sum_{i=1}^{n} s^{i} / n$ of political news signals. 'Expected partisan conflict', refers to the posterior mean of partisan conflict given the set of available information at that time $\Omega$. It is denoted by $\hat{c}^{\prime}(\bar{s}) \equiv \mathbb{E}(c \mid \Omega)$. The term 'political uncertainty' refers to the posterior variance of partisan conflict given $\Omega$, $\operatorname{Var}(c \mid \Omega)$.

In a model with perfect information, expected partisan conflict is simply $c$ and its variance is zero. Under imperfect information, agents compute the expected value of $c$ as a function of their beliefs. Right after an election, political uncertainty is large and the estimate $\hat{c}^{\prime}(\bar{s})$ imprecise. As agents receive information, their beliefs are updated and, over time, they become closer to the true value of $c$. As shown in Appendix 7.4, expected partisan conflict satisfies

$$
\hat{c}^{\prime}(\bar{s}) \equiv E(c \mid \Omega)=\frac{\hat{\beta}^{\prime}(\bar{s})}{\hat{\alpha}^{\prime}-1} .
$$

The set of available information to the investor is now $\Omega=\{\tau, i, \bar{s}, \hat{\alpha}, \hat{\beta}(\bar{s})\}$. Relative to the previous sections, the status quo level of taxes $\tau$ and the identity of the proposer $i$ are in the information set $\Omega$, but $c$ is not. Instead, the investor knows the posterior parameters of the distribution of $c$ once signals have been incorporated and beliefs have been updated.

The posterior mean of partisan conflict, $\hat{c}^{\prime}(\bar{s})$, can be written as a weighted sum between the prior mean and the sample mean as follows

$$
\hat{c}^{\prime}(\bar{s})=\omega \bar{s}+(1-\omega) \hat{c} \quad \text { with } \quad \omega=\frac{n}{\hat{\alpha}+n-1} .
$$

In this model, expected partisan conflict $\hat{c}^{\prime}(\bar{s})$ changes for two reasons: (i) because there is an election every $T$ periods, where true partisan conflict $c$ changes and priors are re-set according to eq. (11); and (ii) because between elections (when $c$ is unchanged), agents 
receive signals $\bar{s}>0$ about the true value of partisan conflict. These (noisy) signals allow them to more accurately estimate partisan conflict, following eq. (14). Given the analysis in the previous sections, we are mostly interested in understanding the latter. The effects of new signals on policy and investment decisions is analyzed next.

\subsection{The Effects of PCI}

Higher values of the PCI $\bar{s}$, keeping everything else constant - including the true value of $c$ result in higher expected partisan conflict

$$
\frac{\hat{c}^{\prime}(\bar{s})}{\partial \bar{s}}>0
$$

and more political uncertainty

$$
\frac{\operatorname{Var}(c \mid \Omega)}{\partial \bar{s}}>0
$$

The first result follows from expression (14). The second result, from the expression determining the posterior variance of $c$, or political uncertainty (see Appendix 7.5 for derivation):

$$
\operatorname{Var}(c \mid \Omega)=\frac{\hat{c}^{\prime}(\bar{s})^{2}}{\left(\hat{\alpha}^{\prime}-2\right)}
$$

Figure 5 depicts the evolution of signals and beliefs for a simulated economy that lasts $T=9$ periods (and assuming $c=10$ ). 

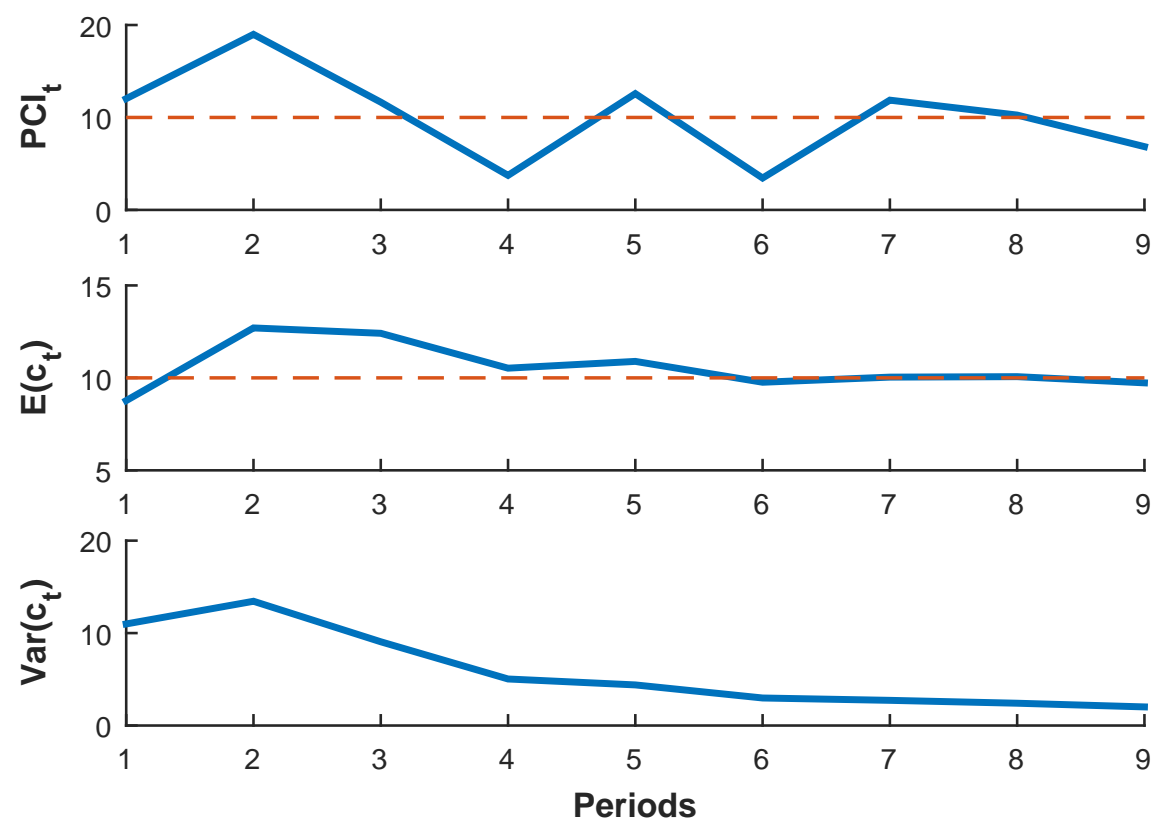

Figure 5: Evolution of signals $\bar{s}$, or PCI (first plot), posterior beliefs about partisan conflict, $E(c \mid \Omega)=$ $\hat{c}^{\prime}$ (second plot), and political uncertainty $\operatorname{Var}(c \mid \Omega)$ (third plot).

Note: Parameter values $c=10, \alpha_{0}=4, \beta_{0}=10, n=5, T=9$.

The first plot in Figure 5 shows the evolution of the partisan conflict index $\bar{s}$ over time (solid line) together with the true value of partisan conflict $c$ (dotted line). As agents observe increases in the number of newspaper articles reporting political disagreement $\bar{s}$, their beliefs about true partisan conflict $\hat{c}^{\prime}$ rise, as seen in the second plot. The effect of these signals is larger in the first few periods (that is, right after an election), as investors have little information about $c$. As time goes by, signals are given relatively lower weight. The last plot, which depicts the evolution of $\operatorname{Var}(c \mid \Omega)$, illustrates that uncertainty about partisan conflict $c$ decreases over time. However, the decline is non-monotonic, as extremely high realizations of the PCI (as seen in period 2) may introduce significant political uncertainty. Notice that higher partisan conflict is not always associated with greater political uncertainty. While higher realizations of $\bar{s}$ increase $\operatorname{Var}(c \mid \Omega)$, its effect is tamed by the fact that as agents learn about the true value of partisan conflict, they give a smaller weight to $\bar{s}$. This can be seen by re-writing eq. (15) for a given period $t$ as follows,

$$
\operatorname{Var}_{t}\left(c \mid \Omega_{t}\right)=\frac{\hat{c}_{t+1}\left(\bar{s}_{t}\right)^{2}}{\left(\alpha_{0}+t n-2\right)}
$$

where we just substituted out $\hat{\alpha}_{t+1}=\alpha_{0}+t n-2$. Note that as we move forward in time 
there are two effects: first, there is a new realization of $\bar{s}_{t}$ (which increases the numerator of $\left.\operatorname{Var}_{t}\left(c \mid \Omega_{t}\right)\right)$; second, there is an increase in the denominator of $n$ through $t$. This implies that political uncertainty may increase under extremely large realizations of PCI (as in $t=5$ ), but that would not necessarily be the case for moderate increases (as in $t=7$ ). If no elections took place, then $\hat{c}_{t+1}\left(\bar{s}_{t}\right)$ would converge to $c$ as $t \rightarrow \infty$ and $\operatorname{Var}_{t}\left(c \mid \Omega_{t}\right)$ would converge to zero. That is, agents would eventually learn the true value of partisan conflict.

We can compute the expected probability of a crisis and the expected probability of a tax reform as functions of the PCI analytically, as shown in Lemma 5.1.

Lemma 5.1 The expected likelihood of a crisis under imperfect information, as a function of the PCI $\bar{s}$, satisfies

$$
\mathbb{E}(\mathcal{P}(c / \Omega)) \equiv \hat{\mathcal{P}}(\bar{s})=\frac{1}{m}\left(\epsilon+\theta \frac{\left[\hat{\beta}^{\prime}(\bar{s})\right]^{\hat{\alpha}^{\prime}}}{\left[1+\hat{\beta}^{\prime}(\bar{s})\right]^{\hat{\alpha}^{\prime}}}\right)
$$

where

$$
\hat{\alpha}^{\prime}=\hat{\alpha}+n, \quad \text { and } \quad \hat{\beta}^{\prime}(\bar{s})=\hat{\beta}+n \bar{s} .
$$

The expected probability of a tax reform under imperfect information, as a function of $\bar{s}$, satisfies

$$
\mathbb{E}\left(\mathcal{Q}_{i}(c / \Omega)\right) \equiv \hat{\mathcal{Q}}_{i}(\bar{s}, \tau)=\left\{\begin{array}{cl}
1-\frac{\theta}{v\left|\tau-\tau_{i}\right|} \frac{\left[\hat{\beta}^{\prime}(\bar{s})\right]^{\hat{\alpha}^{\prime}}}{\left[1+\hat{\beta}^{\prime}(\bar{s})\right]^{\hat{\alpha}^{\prime}}} & \text { if } \tau \neq \tau_{i} \\
0 & \text { otherwise }
\end{array}\right.
$$

Proof 5.1 See Appendix 7.6.

When investors observe an increase in the number of articles reporting partisan conflict in their sample, beliefs about $c$ are updated upwards. The increase in $\bar{s}$ affects their perception about the degree of effort that will be exerted by legislators and hence the expected probability of a crisis and the expected probability of a tax reform, as the following corollary shows.

Corollary 5.1 Higher values of the PCI $\bar{s}$, keeping everything else constant (including the true value of $c$ ), result in

i. Higher tails risks

$$
\frac{\partial \hat{\mathcal{P}}(\bar{s})}{\partial \bar{s}}>0 .
$$

ii. (Weakly) Lower likelihood of tax reforms

$$
\frac{\partial \hat{\mathcal{Q}}_{i}(\bar{s}, \tau)}{\partial \bar{s}} \leq 0
$$


Proof 5.2 These follow from differentiating eqs. (16) and (17), respectively. Q.E.D.

Because investors change their beliefs about the likelihood of recessions and tax changes, the increase in the PCI will affect their investment decisions. It is interesting to note that they respond to news despite the fact that true partisan conflict $c$ remains unchanged. As mentioned before, the intensity of this reaction will depend on the number of periods since the last election: as time goes by, news are less informative, and hence the intensity of the response is expected to be lower. The following section analyzes the effects of the PCI on investment decisions.

\subsection{Partisan Conflict, News, and Investment}

The timing of events under imperfect information can be summarized as follows

- At the outset of a given period, firms own capital $K$ and have priors $\hat{\alpha}$ and $\hat{\beta}$. The status-quo tax rate is $\tau$ and the proposer is of type $i$.

- Signals $\left\{s_{1}, \ldots, s_{n}\right\}$ are observed and beliefs are updated.

- Firms observe productivity shocks $\varepsilon$ and $\nu$ and compute $z$.

- Investment decisions $I$ take place.

- The proposer exerts legislative effort to change the economic environment $x$ and/or modify the tax code $n$.

- Production and consumption take place.

- After $T$ periods there is an election, where beliefs are reset according to eq. (11).

Following the steps in Section 2.1, it is easy to compute investment as a function of the information set $\Omega=\{\tau, i, \bar{s}, \hat{\alpha}, \hat{\beta}(\bar{s})\}$ in a non-election period

$$
I(\Omega)=\frac{1}{\gamma}\left[\frac{1}{1+r^{*}} \hat{R}(\Omega)-1\right]
$$

where $\hat{R}(\Omega)$ denotes the after-tax return to investment given the information set $\Omega$.

$$
\hat{R}(\Omega) \equiv \mathbb{E}_{c}\left[\mathbb{E}_{z^{\prime}, \tau^{\prime}}\left(e^{z^{\prime}}\left(1-\tau^{\prime}\right)\right) / \Omega\right]
$$

Note that $\mathbb{E}_{z^{\prime}, \tau^{\prime}}$ refers to the expectation over future TFP shocks and future taxes for a given value of $c$, whereas $\mathbb{E}_{c}$ is the expectation over possible values of $c$ given the posterior 
distribution computed in the previous section. In other words, the inner term reflects the expectation over possible realizations of the economic and political shocks next period for a given distribution of these shocks. It is equivalent to the one computed under perfect information. The outer expectation term incorporates the fact that agents to not know for sure what true partisan conflict is, and must use a proxy given their prior beliefs and the news signals obtained in the current period. This allows us to specify the after-tax return to investment as a function of the partisan conflict index as follows.

$$
\hat{R}(\Omega)=e^{\frac{2 \mu+\sigma^{2}}{2}}\left\{[1-\kappa \hat{\mathcal{P}}(\bar{s})](1-\tau)+\left(\tau-\tau_{i}\right)\left[\hat{\mathcal{Q}}_{i}(\bar{s}, \tau)-\kappa \mathbb{E}_{c}\left[\mathcal{P}(c) \mathcal{Q}_{i}(c, \tau)\right]\right\}\right]
$$

where $\hat{\mathcal{P}}(\bar{s})$ is given by eq. $(16), \hat{\mathcal{Q}}_{i}(\bar{s}, \tau)$ by eq. $(17)$, and the last expectation term by:

$$
\mathbb{E}_{c}\left[\mathcal{P}(c) \mathcal{Q}_{i}(c, \tau)\right]=\frac{1}{m}\left(\epsilon \hat{\mathcal{Q}}_{i}(c, \tau)+\theta \hat{\beta}^{\prime \hat{\alpha}^{\prime}}\left[\frac{1}{\left(1+\hat{\beta}^{\prime}\right)^{\hat{\alpha}^{\prime}}}-\frac{\theta}{v\left|\tau-\tau_{i}\right|} \frac{1}{\left(2+\hat{\beta}^{\prime}\right)^{\hat{\alpha}^{\prime}}}\right]\right)
$$

The following proposition characterizes investment decisions as a function of the partisan conflict index $\bar{s}$.

Proposition 5.1 Let $t<T$ and Assumption 2.1 hold. If $\kappa>\tilde{\kappa}$, an increase in the PCI reduces private investment

$$
\frac{\partial I(\bar{s})}{\partial \bar{s}}<0
$$

with $\tilde{\kappa}$ defined in Appendix 7.7.

Proof 5.3 See Appendix 7.7

This Lemma establishes our main result, namely, that aggregate investment declines when the partisan conflict indicator rises. It holds under the assumption that the crisis is severe enough. Intuitively, as investors observe a large proportion of news articles reporting political disagreement, they update their beliefs about partisan conflict upwards. The increase in $\hat{c}(\bar{s})$ implies that less legislative effort is expected. Hence, effective measures aimed at preventing crises are expected not to be undertaken. To the extent that crises are detrimental enough for investors (e.g. $\kappa$ is sufficiently big), expected returns are lower, and so are the incentives to invest.

Why is the assumption on $\kappa$ necessary? Because, expectations of higher partisan conflict not only increase the probability of a crisis $\hat{\mathcal{P}}(\bar{s})$ but also lower the expected probability of a tax reform $\hat{\mathcal{Q}}_{i}(\bar{s}, \tau)$. In particular, stalemate reduces the chances of a tax hike. When current 
taxes are low relative to the proposer's desired value, $\tau<\tau_{i}$, news about partisan conflict reduce the expected likelihood of a tax-hike. Keeping the probability of a crisis constant, this pushes up expected returns. When the crisis is severe enough, the positive effect of gridlock on fiscal policy (and returns) is dwarfed by the negative effect of an expected increase in the probability of a recession. As a result, expected returns decline.

Notice that real investment is affected by $\bar{s}$ even though there is no actual change in fundamentals, that is, even though partisan conflict $c$ remains the same. This suggests that perceptions about political dysfunction, and hence decisions depending on these perceptions, may also be affected by the dynamics characterizing the media market.

Impulse Response To illustrate the dynamic response of investment and its determinants to a 'news shock,' I simulate an example economy for 20 periods. The parameters are the same as in the previous examples, namely $\theta=0.5, m=2, \epsilon=0.2, \alpha=10, v=4, \triangle=0.1$, $\kappa=0.9$, the status quo $\operatorname{tax} \tau=\bar{\tau}=0.3$, and the true value of partisan conflict is $c=2$. In addition, I set the interest rate to $r^{*}=0.02$ and $\gamma=2$.
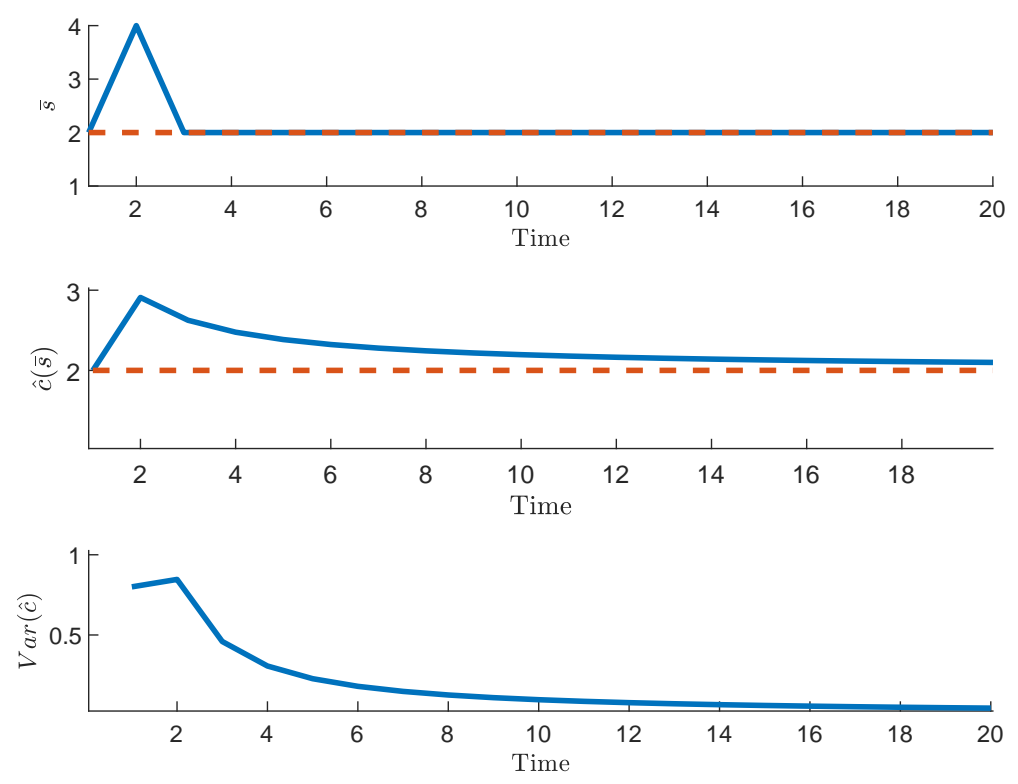

Figure 6: Impulse-response of $\hat{c}(\bar{s})$ and $\operatorname{Var}(\hat{c})$ to a news shock over time. First panel: PCI $\bar{s}$. Second panel: expected partisan conflict $\hat{c}(\bar{s})$. Third panel: political uncertainty, $\operatorname{var}(\hat{c}))$. Parameters: $\theta=0.5, m=2, \epsilon=0.2, \alpha=10, v=4, \triangle=0.1, \kappa=0.9, c=2, r^{*}=0.02, \gamma=2$, and the status quo $\operatorname{tax} \tau=\bar{\tau}=0.3$.

I start the simulation assuming that the prior belief of investors in period 0 is correct. That is, I assume that $\alpha_{0}=2$ and $\beta_{0}=2$ which implies that $\hat{c}_{0}=2$ (this follows from eq. 
13). The partisan conflict index is set at $\bar{s}_{t}=2$ for all $t$ except $t=2$ where $\bar{s}_{2}=4$. This represents a 'news shock.' The evolution of $\bar{s}$ is depicted in the first panel of Figure 6 . Note that if the partisan conflict index was $\bar{s}=2$ every period, then investors would never change their beliefs as they would update expected partisan conflict to $\hat{c}=2$. Due to the news shock, however, they update their beliefs and expected partisan conflict moves upward. This is shown in the second panel of Figure 6, where the solid line is $\hat{c}(\bar{s})$ and the dotted line the true $c=2$. The effect of the news shock dies out eventually, and $\hat{c}$ approaches its true value after about 20 periods. Finally, the third panel of the figure shows political uncertainty, $\operatorname{Var}(\hat{c})$. Uncertainty jumps in the first period as a result of the increase in the PCI, and converges to zero over time.
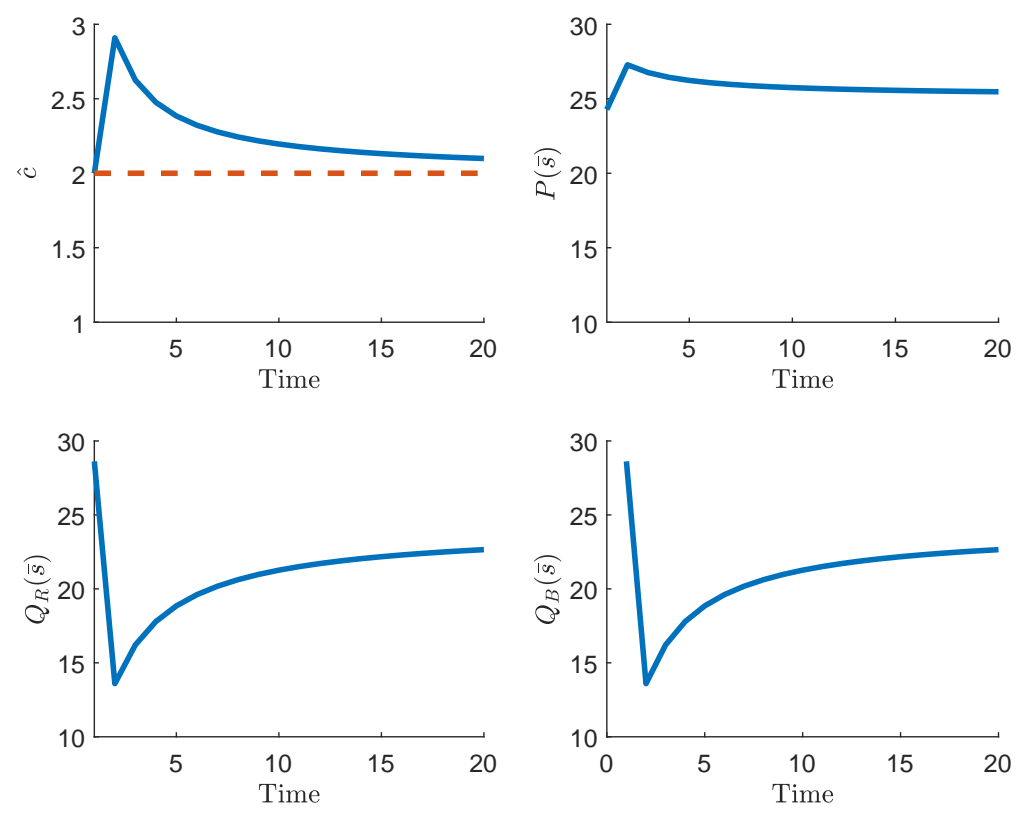

Figure 7: Impulse-response of $\mathcal{P}(\bar{s})$ and $\mathcal{Q}_{i}(\bar{s}, \tau)$ to a news shock over time. Top-left panel: $\hat{c}(\bar{s})$. Top-right panel: $\mathcal{P}(\bar{s})$ in \%. Bottom panels: $\mathcal{Q}_{i}(\bar{s}, \tau)$ for $i=R$ and $i=L$, respectively, in \%. Parameters: $\theta=0.5, m=2, \epsilon=0.2, \alpha=10, v=4, \triangle=0.1, \kappa=0.9, c=2, r^{*}=0.02, \gamma=2$, and the status quo tax $\tau=\bar{\tau}=0.3$.

Figure 7 shows that the increase in expected partisan conflict (top-left panel) induces a spike on the expected probability of a crisis (top-right panel) and a decline in the expected probability of a tax reform (bottom panels). Even though $\bar{s}$ rises for only one period, the change in expectations is persistent (e.g. it takes a long time to die out). The response of $\mathcal{Q}_{R}(\bar{s})$ and $\mathcal{Q}_{L}(\bar{s})$ is identical due to the symmetry assumption in ideal points $\tau_{i}$. The news-shock, through its effect in expected probabilities, changes the expected returns before 
taxes (left panel of Figure 8) and after taxes (right panel of Figure 8). To make the analysis cleaner, it is assumed that the status quo tax remains unchanged at $\bar{\tau}$ through all simulations. It is interesting to note that the decline in expected returns is larger when the proposer is $\mathrm{R}$-winged. This is a result in the elasticity of legislative effort to partisan conflict. In other words, investors understand that an $R$ proposer will be more responsive to an increase in $c$, and hence expect a bigger decline in expected returns when expected partisan conflict rises.
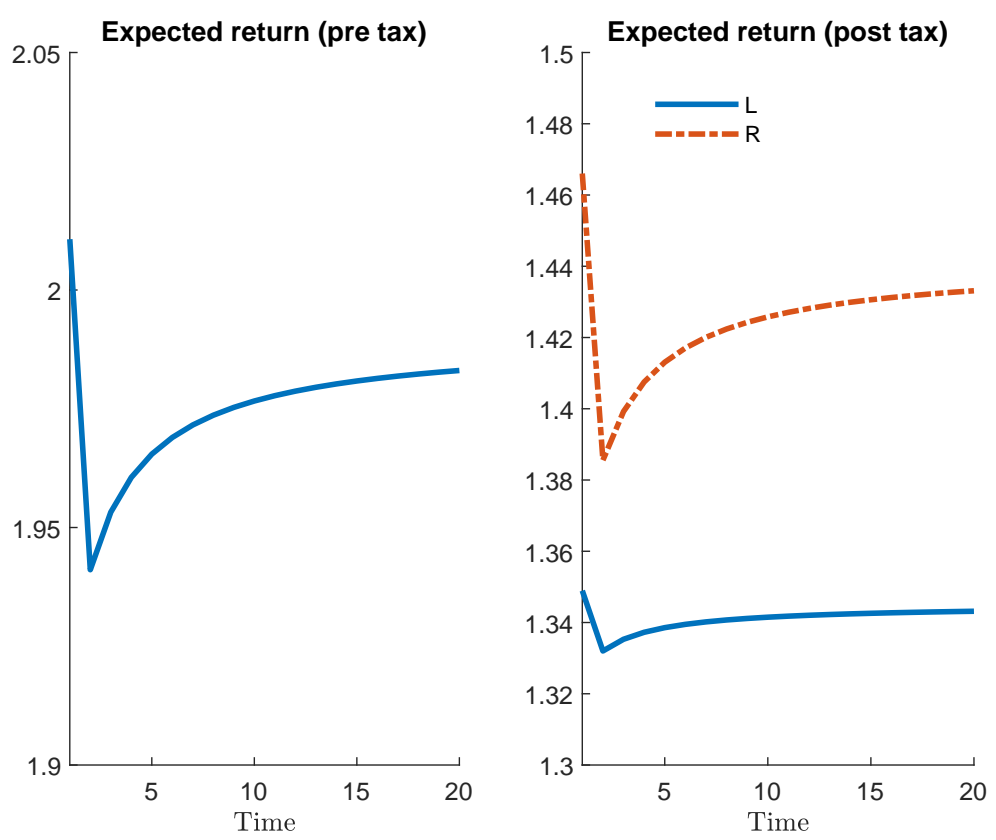

Figure 8: Impulse-response of expected returns before taxes (left panel) and after taxes (right panel) to a news shock over time. Parameters: $\theta=0.5, m=2, \epsilon=0.2, \alpha=10, v=4, \triangle=0.1, \kappa=0.9$, $c=2, r^{*}=0.02, \gamma=2$, and the status quo $\operatorname{tax} \tau=\bar{\tau}=0.3$.

Figure 9 shows how investment reacts to the news shock. Because expected returns after tax decline more when the proposer is $R$, the response of investment is larger. The level of investment, on the other hand, is still larger as a tax-cut is expected with an $R$ proposer when the status quo is $\bar{\tau}$. Even though the news shock lasts only one period, we observe a persistent change in investment. In other words, investors take time to adjust their expectations in response to a large increase in the PCI. The change in behavior is purely expectations' driven, as everything else remains unchanged in this environment. 


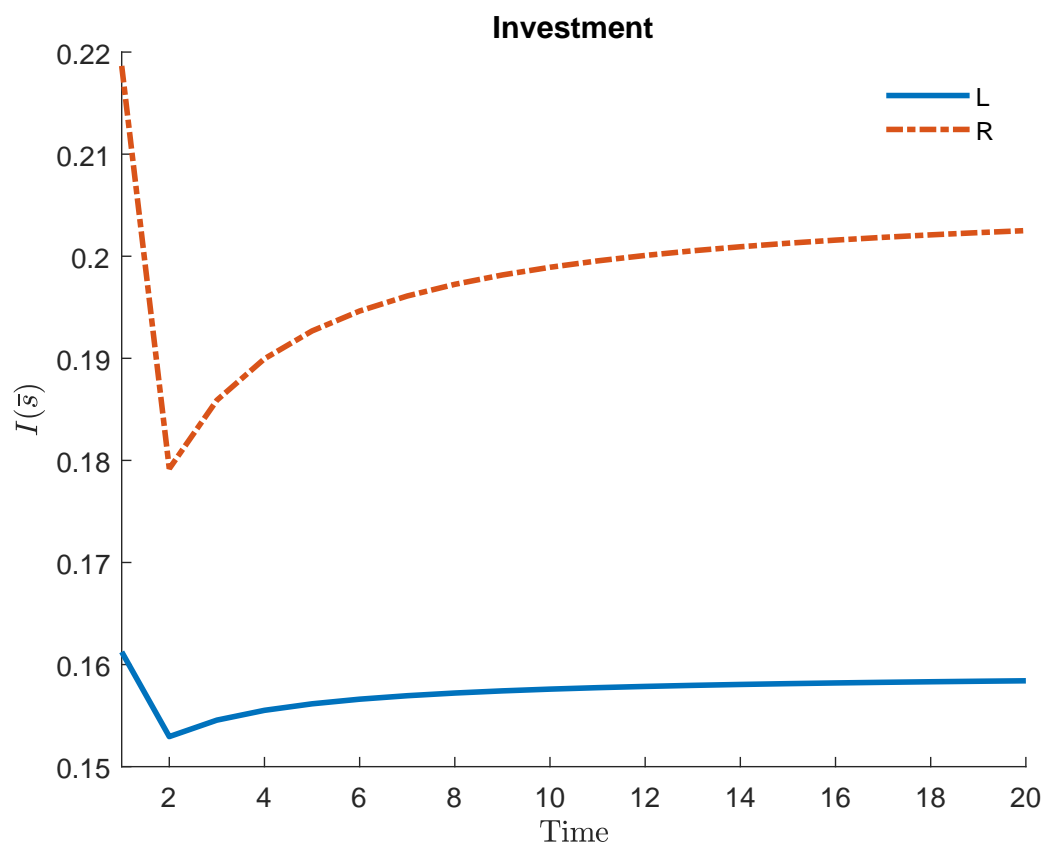

Figure 9: Impulse-response of investment to a news shock over time. Parameters: $\theta=0.5, m=2$, $\epsilon=0.2, \alpha=10, v=4, \triangle=0.1, \kappa=0.9, c=2, r^{*}=0.02, \gamma=2$, and the status quo tax $\tau=\bar{\tau}=0.3$.

\section{Conclusion and extensions}

This paper highlights the relationship between agents' expectations about political discord and their subsequent investment decisions. Partisan conflict is relevant for investment decisions because it affects the efficacy of government policy in preventing bad economic outcomes and the likelihood of tax reforms. Agents do not observe the true degree of political disagreement (and hence the quality of policies), but can create expectations based on the observation of informative signals. These capture information that investors gather from newspaper articles, reports by non-partisan agencies (such as the Congressional Budget Office, Pew Research, Brookings Institution papers, etc.), political discourse and debates or exchange between politicians. Using a Bayesian learning model, I show that increases in the partisan conflict index (a summary of the signals observed) reduces the perceived quality of government intervention (increasing the probability of a negative economic outcome) as well as the chances of a tax reform (which may increase or decrease expected returns). To the extent crises are severe enough, the first effect dominates. This lowers expected returns to investment inducing reductions in aggregate investment. 
This model is clearly very stylized, but it points to a link between the flow of political news and investors' expectations. This affects investors behavior even when the true degree of partisan conflict remains unchanged. I assumed that the only shock to true partisan conflict is the outcome of elections. It would be interesting, however, to extend the model to allow for other shocks to partisan conflict arising at random times (for example through a Poisson process). The rationale is that policymakers must react to unexpected shocks such as a terrorist attack, a natural disaster, a financial crisis triggered by another country, or sovereign default by a trade partner, among others. The degree of conflict at that point in time may change significantly, depending on how controversial the specific issue that needs immediate resolution is. Investors would react by re-setting their priors, which would cause a spike in political uncertainty. These shocks would emphasize the importance of the partisan conflict index, as news signals would be very informative right after the shock.

I also assumed that there is no uncertainty about the state of the economy outside of that caused by political uncertainty. We could consider an environment in which the distribution of returns was subject to shocks - either to the variance of idiosyncratic shocks $\sigma$ or even to the size of the recession $\kappa$ - caused by external factors (such as a war, a financial crisis/recession suffered by a trade partner, a monetary policy shocks, etc.). Agents would react to this additional source of uncertainty by changing their investment decisions, even if the partisan conflict index were constant. Moreover, we would expect policies to react to these shocks in order to stabilize the economy. It would be interesting to analyze such environment, and the implications of this for the relationship between partisan conflict, news, and economic policy uncertainty.

Finally, the assumption of full depreciation and a quadratic cost of adjustment cost facilitated an analytical characterization for the investment rule as a function of signals of partisan conflict. The drawback of this assumption is that investment is independent of the current stock of capital, implying that the model exhibits no dynamics other than those arising from the acquisition of information. Relaxing the model to less than full depreciation or assuming that adjustment costs are proportional to the stock of capital (e.g. a cost on the investment rate rather than over the total level of investment), we could characterize a model with a transition to the ergodic set. Such characterization, however, would require the computation of the model under specific parameters, as investment rules would not be able to be obtained in closed form. In particular, not only current signals would be relevant to compute expectations but also potential future signals over partisan conflict, as each unit of investment would give returns for a long period of time. This could be an interesting extension to the model. The analysis of this environment, while of great interest, is left for future research. 


\section{References}

[1] Alesina, A. And Rosenthal, H. (1995) Partisan politics, divided government, and the economy. Cambridge University Press.

[2] Azzimonti, M. (2018a) 'Does partisan conflict deter FDI inflows to the US?,' NBER Working Paper w22336.

[3] Azzimonti, M. (2018b) "Partisan Conflict and Private Investment," Journal of Monetary Economics, 23, 114-131.

[4] Azzimonti, M. And Talbert, M. (2013) "Polarized business cycles," Journal of Monetary Economics, 67, 47-61.

[5] Bachmann, R., Elstner, S., and Sims, E. (2013) "Uncertainty and economic activity: Evidence from business survey data," American Economic Journal: Macroeconomics, $5(2), 217-249$.

[6] Baker, S., Bloom, N., And Davis, S. (2016) "Measuring economic policy uncertainty," Quarterly Journal of Economics, 131 (4), 1593-1636.

[7] Bloom, N. (2009) "The impact of uncertainty shocks," Econometrica, 77(3), 623-685.

[8] Beaudry, P. And Portier, F. (2006) "Stock prices, news, and economic fluctuations," American Economic Review, 96 (4), 1293-1307.

[9] Beaudry, P. And Portier, F. (2014) "News-driven business cycles: Insights and challenges," Journal of Economic Literature 52 (4), 993-1074.

[10] Belo, F., Gala, V., And Li, J. (2013) "Government spending, political cycles and the cross-section of stock returns," Journal of Financial Economics, 107(2), 305-324.

[11] Bernanke, B. (1983) "Irreversibility, Uncertainty and Cyclical Investment," Quarterly Journal of Economics, 97(1), 85-106.

[12] Canes-Wrone, C. And Park, J.K. (2011) "Electoral business cycles in OECD countries," American Political Science Review, 106(1), 103-122.

[13] Dixit, A. and R. Pyndick (1994) Investment under uncertainty. Princeton University Press, Princeton University, New Jersey.

[14] Durnev, A (2010) The Real Effects of Political Uncertainty: Elections and Investment Sensitivity to Stock Prices. Working paper. 
[15] Fernández-Villaverde, J., Guerrón, P. Kuester, K., and Rubio-Ramírez, J. (2015) "Fiscal volatility shocks and economic activity," American Economic Review, 105(11), 3352-3384.

[16] Fernández-Villaverde, J., and Rubio-Ramírez, J. (2010) "Macroeconomics and volatility: Data, models, and estimation," NBER Working Paper 16618

[17] Gabaix, X. (2008) "Variable rare disasters: A tractable theory of ten puzzles in macrofinance," The American Economic Review, 98(2), 64-67.

[18] Gulen, H. And Ion, M. (2016) "Policy Uncertainty and Corporate Investment, " Review of Financial Studies, 29 (3), 523-564.

[19] Julio, B., and Y. Yook. 2012. Political Uncertainty and Corporate Investment Cycles. Journal of Finance, 67, 4584.

[20] Julio, B. and Y. Yook. 2014. Policy Uncertainty, Irreversibility, and Cross-Border Flows of Capital. Finance and Economics Discussion Series Divisions of Research \& Statistics and Monetary Affairs Federal Reserve Board, Washington, D.C.

[21] Kelly, B. And Jiang, H. (2014) "Tail risk and asset prices, " The Review of Financial Studies, 27(10), 2841-2871.

[22] Kelly, B., Pastor, L., And Veronesi, P. (2013) "The price of political uncertainty: Theory and evidence from the option market," NBER Working Paper 19812.

[23] PAstor, L. And Veronesi, P. (2013) "Political uncertainty and risk premia," Journal of Financial Economics, 110(3), 520-545.

[24] Pyndick, A. (1993) "A note on competitive investment under uncertainty," American Economic Review, 273-277.

[25] SHen, W. (2015) "News, disaster risk, and time-varying uncertainty," Journal of Economic Dynamics and Control, 51, 459-479.

[26] Stokey, N. (2013) "Wait-and-See: Investment Options under Policy Uncertainty," NBER Working Paper 19630. 


\section{Appendix}

\subsection{Proof of Lemma 3.2}

EPU satisfies

$$
\operatorname{Var}(\tau \mid \Omega)=\mathcal{Q}_{i}(c, \tau)\left[1-\mathcal{Q}_{i}(c, \tau)\right]\left(\tau_{i}-\tau\right)^{2}
$$

Hence,

$$
\frac{\partial \operatorname{Var}(\tau \mid \Omega)}{\partial c}=\frac{\partial \mathcal{Q}_{i}(c, \tau)}{\partial c}\left(1-2 \mathcal{Q}_{i}(c, \tau)\right)\left(\tau_{i}-\tau\right)^{2} .
$$

The expression is positive when $\mathcal{Q}_{i}(c, \tau)<0.5$ and negative otherwise. In other words, when

$$
\mathcal{Q}_{i}(c, \tau)=1-\frac{\theta}{v} e^{-\frac{1}{c}} \frac{1}{\left|\tau_{i}-\tau\right|}<0.5
$$

Solving for $c$, this condition holds when $c<\varsigma$ as defined in the Lemma.

\subsection{Proof of Lemma 4.1}

From the definition of $z$,

$$
\begin{aligned}
E\left(e^{z^{\prime}} / c\right) & =E\left(e^{\epsilon^{\prime}+\nu^{\prime}} / c\right) \\
& =e^{\frac{2 \mu+\sigma^{2}}{2}} E\left(e^{\nu^{\prime}} / c\right) \\
& =e^{\frac{2 \mu+\sigma^{2}}{2}}(1-\kappa \mathcal{P}(c))
\end{aligned}
$$

Hence

$$
\partial E\left(e^{z^{\prime}} / c\right) / \partial c=-e^{\frac{2 \mu+\sigma^{2}}{2}} \kappa \partial \mathcal{P} / \partial c<0
$$

\subsection{Posterior Distribution Derivation}

Suppose that we observe $n$ signals $s=\left\{s_{1}, \ldots, s_{n}\right\}$, which are mutually independent given $c$, and $s_{i} \sim \exp (c)$. Then, the likelihood is

$$
\begin{aligned}
L(c \mid s) & =\prod_{i=1}^{n} \frac{1}{c} e^{-\frac{s_{i}}{c}} \\
& =\frac{1}{c^{n}} e^{-\frac{n \bar{s}}{c}}
\end{aligned}
$$


where $\bar{s}=\frac{1}{n} \sum_{i=1}^{n} s_{i}$. A conjugate inverse gamma prior $I G(\hat{\alpha}, \hat{\beta})$ has pdf

$$
f(c)=\frac{\hat{\beta}^{\hat{\alpha}} c^{-\hat{\alpha}-1} e^{-\frac{\hat{\beta}}{c}}}{\Gamma(\hat{\alpha})} \quad x>0
$$

where $\Gamma(\hat{\alpha})$ denotes the Gamma function. By Bayes' rule,

$$
\begin{aligned}
p(c \mid s) & \propto p(s \mid c) p(c) \\
& \propto c^{-\hat{\alpha}-1} e^{-\frac{\hat{\beta}}{c}} \frac{1}{c^{n}} e^{-\frac{n \bar{s}}{c}} \\
& \propto c^{-(\hat{\alpha}+n)-1} e^{-\frac{\hat{\beta}+n \bar{s}}{c}} \\
& \sim I G(\hat{\alpha}+n, \hat{\beta}+n \bar{s}) .
\end{aligned}
$$

Let $\hat{\alpha}_{0}=\alpha_{0}$ and $\hat{\beta}_{0}=\beta_{0}$. Then, the posterior parameters evolve according to

$$
\hat{\alpha}^{\prime}=\hat{\alpha}+n \quad \text { and } \quad \hat{\beta}^{\prime}=\hat{\beta}+n \bar{s},
$$

where primes denote future periods.

\subsection{Expected Partisan Conflict Derivation}

To compute the posterior mean of $c$, note that

$$
\begin{aligned}
E\left(c^{k}\right) & =\int_{0}^{\infty} c^{k} \frac{\hat{\beta}^{\hat{\alpha}} c^{-\hat{\alpha}-1} e^{-\frac{\hat{\beta}}{c}}}{\Gamma(\hat{\alpha})} d c \\
& =\frac{\hat{\beta}^{\hat{\alpha}}}{\Gamma(\hat{\alpha})} \int_{0}^{\infty} c^{k-\hat{\alpha}-1} e^{-\frac{\hat{\beta}}{c}} d c \\
& =\frac{\hat{\beta}^{\hat{\alpha}}}{\Gamma(\hat{\alpha})} \frac{\Gamma(\hat{\alpha}-k)}{\hat{\beta}^{\hat{\alpha}-k}} \int_{0}^{\infty} \hat{\beta}^{\hat{\alpha}-k} c^{-(\hat{\alpha}-k)-1} \frac{e^{-\frac{\hat{\beta}}{c}}}{\Gamma(\hat{\alpha}-k)} d c \\
& =\hat{\beta}^{k} \frac{\Gamma(\hat{\alpha}-k)}{\Gamma(\hat{\alpha})}=\hat{\beta}^{k} \frac{\Gamma(\hat{\alpha}-k)}{(\hat{\alpha}-1) \ldots(\hat{\alpha}-k) \Gamma(\hat{\alpha}-k)} \\
& =\frac{\hat{\beta}^{k}}{(\hat{\alpha}-1) \ldots .(\hat{\alpha}-k)} .
\end{aligned}
$$

This implies that

$$
E(c \mid \Omega)=\frac{\hat{\beta}}{\hat{\alpha}-1},
$$




\subsection{Political Uncertainty Derivation}

Since $\operatorname{Var}(c \mid \Omega)=E\left(c^{2} \mid \Omega\right)-[E(c \mid \Omega)]^{2}$, and $E(c \mid \Omega)$ was derived in Appendix 7.4 above, we only need to compute $E\left(c^{2} \mid \Omega\right)$.

$$
E\left(c^{2} \mid \Omega\right)=\frac{\hat{\beta}^{2}}{(\hat{\alpha}-1)(\hat{\alpha}-2)}
$$

Hence, the variance is

$$
\operatorname{Var}(c \mid \Omega)=\frac{\hat{\beta}^{2}}{(\hat{\alpha}-1)^{2}(\hat{\alpha}-2)}
$$

\subsection{Proof Lemma 5.1}

To compute $\hat{\mathcal{P}}(\bar{s})$ recall that

$$
\mathcal{P}(c)=\frac{1}{m}\left(\epsilon+\theta e^{-\frac{1}{c}}\right) .
$$

At the time of making an investment decision, agents do not know the true value of $c$. Their information set consists of a prior $\hat{\beta}$ and $\hat{\alpha}$, and a set of signals $\left\{s^{j}\right\}_{j=1}^{n}$. Given the signals, agents update their priors so that $\hat{\alpha}^{\prime}=\hat{\alpha}+n$ and $\hat{\beta}^{\prime}(\bar{s})=\hat{\beta}+n \bar{s}$, with $\bar{s}=\sum_{j} s_{t}^{j}$. Moreover, they know that $c$ is distributed according to an $I G\left(\hat{\alpha}^{\prime}, \hat{\beta}^{\prime}(\bar{s})\right)$. Given this distribution, their best guess for the probability of a recession or crisis is

$$
\mathbb{E}(\mathcal{P}(c / \Omega)) \equiv \hat{\mathcal{P}}(\bar{s})=E\left[\frac{1}{m}\left(\epsilon+\theta e^{-\frac{1}{c}}\right) \mid \Omega\right]
$$

Using the fact that $c \sim I G\left(\hat{\alpha}^{\prime}, \hat{\beta}^{\prime}(\bar{s})\right)$, we obtain

$$
\hat{\mathcal{P}}(\bar{s})=\int_{0}^{\infty} \frac{1}{m}\left(\epsilon+\theta e^{-\frac{1}{c}}\right) \frac{\hat{\beta}^{\prime \hat{\alpha}^{\prime}} e^{-\frac{\hat{\beta}^{\prime}}{c}} c^{-\hat{\alpha}^{\prime}-1}}{\Gamma\left(\hat{\alpha}^{\prime}\right)} d c
$$

where dependence of $\beta^{\prime}$ on $\bar{s}$ has been suppressed for readability and $\Gamma\left(\hat{\alpha}^{\prime}\right)$ denotes the Gamma function, $\Gamma(\alpha)=\int_{0}^{\infty} x^{\alpha-1} e^{-x} d x$. This is equivalent to

$$
\hat{\mathcal{P}}(\bar{s})=\frac{1}{m} \epsilon+\frac{1}{m} \theta \int_{0}^{\infty} e^{-\frac{1}{c}} \frac{\hat{\beta}^{\prime \hat{\alpha}^{\prime}} e^{-\frac{\hat{\beta}^{\prime}}{c}} c^{-\hat{\alpha}^{\prime}-1}}{\Gamma\left(\hat{\alpha}^{\prime}\right)} d c,
$$


Multiplying and dividing by $\tilde{\beta}^{\hat{\alpha}^{\prime}}$, where $\tilde{\beta}^{\prime}=1+\hat{\beta}^{\prime}$, and re-arranging, we obtain

$$
\hat{\mathcal{P}}(\bar{s})=\frac{1}{m} \epsilon+\frac{1}{m} \theta \frac{\hat{\beta}^{\prime \hat{\alpha}_{t}}}{\left(1+\hat{\beta}^{\prime}\right)^{\hat{\alpha}^{\prime}}} \underbrace{\int_{0}^{\infty} \frac{\tilde{\beta}^{\prime \hat{\alpha}^{\prime}} e^{-\frac{\tilde{\beta}^{\prime}}{c}} c^{-\tilde{\alpha}^{\prime}-1}}{\Gamma(\tilde{\alpha})} d c}_{=1} .
$$

which delivers eq. (16).

To compute $\hat{\mathcal{Q}}_{i}(\bar{s}, \tau)$ recall that

$$
\mathcal{Q}_{i}(c, \tau)=\left\{\begin{array}{cl}
1-\frac{\theta}{v\left|\tau-\tau_{i}\right|} e^{-\frac{1}{c}} & \text { if } \tau \neq \tau_{i} \\
0 & \text { otherwise }
\end{array}\right.
$$

Then, when $\tau \neq \tau_{i}$,

$$
\mathbb{E}\left(\mathcal{Q}_{i}(c / \Omega)\right) \equiv \hat{\mathcal{Q}}_{i}(\bar{s}, \tau)=E\left[1-\frac{\theta}{v\left|\tau-\tau_{i}\right|} e^{-\frac{1}{c}} \mid \Omega\right],
$$

Using the fact that $c \sim I G\left(\hat{\alpha}^{\prime}, \hat{\beta}^{\prime}(\bar{s})\right)$, and re-arranging following similar steps to the ones above, we obtain eq. (17)

Q.E.D.

\subsection{Proof Lemma 5.1}

From eq. (18),

$$
\operatorname{sign} \frac{\partial I(\bar{s})}{\partial \bar{s}}=\operatorname{sign} \hat{R}(\Omega) .
$$

The expected value of after-tax returns can be written, after some manipulation, as

$$
\begin{aligned}
\hat{R}(\Omega) & =e^{\frac{2 \mu+\sigma^{2}}{2}}\left\{[1-\kappa \hat{\mathcal{P}}(\bar{s})](1-\tau)+\left(\tau-\tau_{i}\right) \hat{\mathcal{Q}}_{i}(\bar{s}, \tau)\left(1-\frac{\epsilon \kappa}{m}\right)\right. \\
& \left.-\left(\tau-\tau_{i}\right) \frac{\theta \kappa}{m} \beta^{\prime \hat{\alpha}^{\prime}}\left[\frac{1}{\left(1+\hat{\beta}^{\prime}\right)^{\hat{\alpha}^{\prime}}}-\frac{\theta}{v\left|\tau-\tau_{i}\right|} \frac{1}{\left(2+\hat{\beta}^{\prime}\right)^{\hat{\alpha}^{\prime}}}\right]\right\}
\end{aligned}
$$

Taking derivatives,

$$
\begin{aligned}
& \frac{\partial \hat{R}(\Omega)}{\partial \bar{s}}=e^{\frac{2 \mu+\sigma^{2}}{2}}\left\{-(1-\tau) \kappa \frac{\partial \hat{\mathcal{P}}}{\partial \bar{s}}+\left(\tau-\tau_{i}\right) \frac{\partial \hat{\mathcal{Q}}_{i}}{\partial \bar{s}}\left(1-\frac{\epsilon \kappa}{m}\right)\right. \\
& \left.-\left(\tau-\tau_{i}\right) \frac{\theta \kappa}{m} \frac{\partial \hat{\beta}^{\prime}}{\partial \bar{s}} \hat{\alpha}^{\prime}\left[\frac{\hat{\beta}^{\hat{\alpha}^{\prime}-1}}{\left(1+\hat{\beta}^{\prime}\right)^{\hat{\alpha}^{\prime}+1}}+\frac{\theta}{v\left|\tau-\tau_{i}\right|} \frac{1}{\left(2+\hat{\beta}^{\prime}\right)^{\hat{\alpha}^{\prime}+1}}\right]\right\}
\end{aligned}
$$


There are three cases to consider, depending on whether $\tau \lesseqgtr \tau_{i}$

Case 1: When $\tau=\tau_{i}$, then

$$
\frac{\partial \hat{R}(\Omega)}{\partial \bar{s}}=-e^{\frac{2 \mu+\sigma^{2}}{2}}(1-\tau) \kappa \frac{\partial \hat{\mathcal{P}}}{\partial \bar{s}}<0
$$

regardless of the value of $\kappa$ because $\hat{\mathcal{P}}$ is increasing in $\bar{s}$.

Case 2: When $\tau>\tau_{i}$, then $\frac{\partial \hat{R}(\Omega)}{\partial \bar{s}}<0$. This follows by noting that $\hat{\mathcal{P}}$ is increasing in $\bar{s}$ and $\frac{\partial \hat{\mathcal{Q}}_{i}}{\partial \bar{s}}<0$, so all the terms in eq. (22) are negative.

Hence, expected after-tax returns are decreasing in the news shock when taxes are expected to remain constant or when the proposer is expected to introduce a tax-cut.

Case 3: When $\tau<\tau_{i}$, on the other hand, the second and third terms in eq. (22) are positive whereas the first term is negative. Let

$$
\Psi=\frac{\beta^{\prime \hat{\alpha}^{\prime}-1}}{\left(1+\hat{\beta}^{\prime}\right)^{\hat{\alpha}^{\prime}+1}}
$$

Then, we can write

$$
\frac{\partial \hat{\mathcal{P}}}{\partial \bar{s}}=\frac{\partial \hat{\beta}^{\prime}}{\partial \bar{s}} \hat{\alpha}^{\prime} \frac{\theta}{m} \Psi
$$

and

$$
\frac{\partial \hat{\mathcal{Q}}_{i}}{\partial \bar{s}}=-\frac{\partial \hat{\beta}^{\prime}}{\partial \bar{s}} \hat{\alpha}^{\prime} \frac{\theta}{v\left|\tau-\tau_{i}\right|} \Psi
$$

Replacing these in eq. (22) and re-arranging, we can see that

$$
\frac{\partial \hat{R}(\Omega)}{\partial \bar{s}}=e^{\frac{2 \mu+\sigma^{2}}{2}}\left\{\kappa \frac{\partial \hat{\beta}^{\prime}}{\partial \bar{s}} \hat{\alpha}^{\prime} \frac{\theta}{m}\left[-\Psi\left(1-\tau_{i}\right)+\Psi \frac{\epsilon}{v}+\frac{\theta}{v\left(2+\hat{\beta}^{\prime}\right)^{\hat{\alpha}^{\prime}+1}}\right]-\left(\tau_{i}-\tau\right) \frac{\partial \hat{\mathcal{Q}}_{i}}{\partial \bar{s}}\right\}
$$

Defining

$$
\tilde{\kappa}=\frac{\Psi}{\frac{1}{m}\left[v \Psi\left(1-\tau_{i}\right)-\epsilon \Psi-\frac{\theta}{\left(2+\hat{\beta}^{\prime}\right)^{\hat{\alpha}^{\prime}+1}}\right]},
$$

we can see that if $\kappa>\tilde{\kappa}$, then $\frac{\partial \hat{R}(\Omega)}{\partial \bar{s}}<0$.

Q.E.D. 